EMBRYARIDDLE
Aeronautical University

SCHOLARLY COMMONS

\section{International Journal of Aviation,} Aeronautics, and Aerospace

\title{
Low Reynolds Number Numerical Simulation of the Aerodynamic Coefficients of a 3D Wing
}

\author{
Khurshid Malik \\ International Islamic University - Malaysia, khurshid.mlk@gmail.com \\ Waqar Asrar \\ International Islamic University - Malaysia, waqar@iium.edu.my \\ Erwin Sulaeman \\ International Islamic University Malaysia, esulaeman@iium.edu.my
}

Follow this and additional works at: https://commons.erau.edu/ijaaa

Part of the Aerodynamics and Fluid Mechanics Commons

\section{Scholarly Commons Citation}

Malik, K., Asrar, W., \& Sulaeman, E. (2018). Low Reynolds Number Numerical Simulation of the Aerodynamic Coefficients of a 3D Wing. International Journal of Aviation, Aeronautics, and Aerospace, 5(1). https://doi.org/10.15394/ijaaa.2018.1209

This Article is brought to you for free and open access by the Journals at Scholarly Commons. It has been accepted for inclusion in International Journal of Aviation, Aeronautics, and Aerospace by an authorized administrator of Scholarly Commons. For more information, please contact commons@erau.edu. 
Historically, a large number of studies have been done on the capability of simulation as a key tool in predicting aerodynamic behavior (Anderson, 2003; Anderson et al., 1995) to determine the overall performance and stability of an airplane, Unmanned Aerial Vehicle (UAV) and Micro Air Vehicle MAV. The simulation consisting of the six aerodynamic components and their derivatives are vital which may be obtained from wind tunnel experiments as well as through Computational Fluid Dynamics (CFD) simulation (note: Please see appendix 1 for terminology).

CFD can be used for the prediction of aerodynamic properties for $2 \mathrm{D}$ or $3 \mathrm{D}$ wings. Several studies have been done on 2D/3D finite wings to investigate the ability of STAR CCM+ to compute lift, drag, and pitching moments. (Sagmo et al., 2016, Bui, 2016, Garcia et al., 2016, Shankara and Snyder, 2012, Narayana et al., 2005).

Experimental data on the three main aerodynamic components; lift coefficient $\left(\mathrm{C}_{\mathrm{L}}\right)$, drag coefficient $\left(\mathrm{C}_{\mathrm{D}}\right)$ and pitching moment coefficient $\left(\mathrm{C}_{\mathrm{M}}\right)$ on a flat plate wing at low Reynolds numbers have been made available in the literature by (Ananda et al., 2015, Pelletier and Mueller, 2000, Shields and Mohseni, 2012). The behavior of a 3D wing, analyzing the forces (lift, drag \& normal) on several finite wings of small to large aspect ratio has been experimentally investigated at low Reynolds number (Ortiz et al., 2015). Their results stated that lift to drag ratio (L/D ratio) follows the inverse tangent of the angle of incidence for almost all experimental cases.

Wind tunnel experiment on ten flat plates with different taper ratios $(\lambda) 0.5$, $0.75, \& 1$ and aspect ratio (AR) $2,3,4, \& 5$ was carried out at Reynolds number ranging from $5 \times 10^{4}$ to $1.5 \times 10^{5}$ by Ananda et al., 2015, using a threecomponent force balance. Similar work on the rectangular and tapered flat plate wings ( $\mathrm{AR}=0.75,1,1.5$, and 3) were performed at Reynolds numbers between $5 \times 10^{4}$ and $1 \times 10^{5}$ in a wind tunnel by (Shields and Mohseni, 2012). The result of $C_{L}, C_{D}$ and $C_{M}$ variation with angle of attack and Reynolds number was presented.

Mueller and Delauier, (2003), Pelletier and Mueller, (2000), experimentally measured $C_{L}, C_{D}$ and $C_{M}$ for various thin flat plates and cambered plates at Reynolds numbers from $6 \times 10^{4}$ to $2 \times 10^{5}$. A detailed aerodynamic study has been performed by (Abe, 2003) on different aspect ratio flat plates and cambered airfoils at Reynolds numbers below $10^{5}$ using two mechanical balance devices. Only $\mathrm{C}_{\mathrm{L}}, \mathrm{C}_{\mathrm{D}}, \mathrm{C}_{\mathrm{M}}$ \& roll moment coefficient $\left(\mathrm{C}_{l}\right)$ were measured using the two devices. One device measures the $C_{L} \& C_{D}$, and another device extracts the $C_{M} \& C_{l}$. 
To estimate the low-speed longitudinal aerodynamic characteristics, a flatplate model of an advanced fighter configuration was experimented in the NASA Langley Subsonic Basic Research Tunnel. Low-speed longitudinal aerodynamic data were measured over a range of angles of attack from $0^{\circ}$ to $40^{\circ}$ and freestream dynamic pressures from 7.5 psf to $30 \mathrm{psf}(\mathrm{M}=0.07$ to $\mathrm{M}=0.14)$. They are presented as $C_{L}, C_{D}, C_{M}$ and flow-visualization (McGrath et al., 1994).

$\mathrm{C}_{\mathrm{L}}, \mathrm{C}_{\mathrm{D}}$ and $\mathrm{C}_{\mathrm{M}}$ investigation were studied on square plates mounted in a Low-Speed Wind Tunnel (Fail el al., 1959). Study on the flat plate wing was done using a hybrid continuum-particle approach for flows having a Reynolds number varying between 1 and 200 and a Mach number of 0.2 (Sun and Boyd, 2004). Laitone (1997) performed low turbulence wind tunnel testing on NACA 0012 rectangular wing at a low Reynolds number of $2 \times 10^{4}$. He measured only $\mathrm{C}_{\mathrm{L}}, \mathrm{C}_{\mathrm{D}}$ and compared with thin flat and cambered plates. The result indicated that thin plate with $5 \%$ circular arc camber showed the best profile for Reynolds number below $7 \times 10^{4}$ (Laitone, 1997).

This paper presents a CFD study of a finite flat plate wing to estimate the six aerodynamic coefficients and their derivatives at a Reynolds number of $3 \times 10^{5}$ based on the chord length and free stream conditions. To the best of Authors 'knowledge, most of the work on flat plate wings in the open literature report the three components (lift, drag and pitching moment). It seems that there is a lack of data on six aerodynamic coefficients and stability derivatives for a low aspect ratio flat plate wing at low Reynolds number. This data is of vital importance in lowspeed aerodynamics and design for applications to MAVs and UAVs.

\section{Method}

For efficient CFD analysis, CFD geometry fidelity must be as precise as possible. Experience, skill and proper assessment of the effect of flow condition selection are required to study geometry simplification versus fidelity (Rumsey et al., 2011). There are three major steps: 1) Pre-processing, 2) Numerical simulation/Processing, and 3) Post-processing/Result. In pre-processing, a 3-D model was developed using Solid Works. Then boundary and operating condition on unstructured meshing were performed using STAR-CCM+.

\section{Model Details}

A flat plate 3D wing model is selected for this study. It has an aspect ratio of three with no taper. Table 1 shows the 3D flat plate wing model specification. The model and computational domain are shown in Figure 1. 


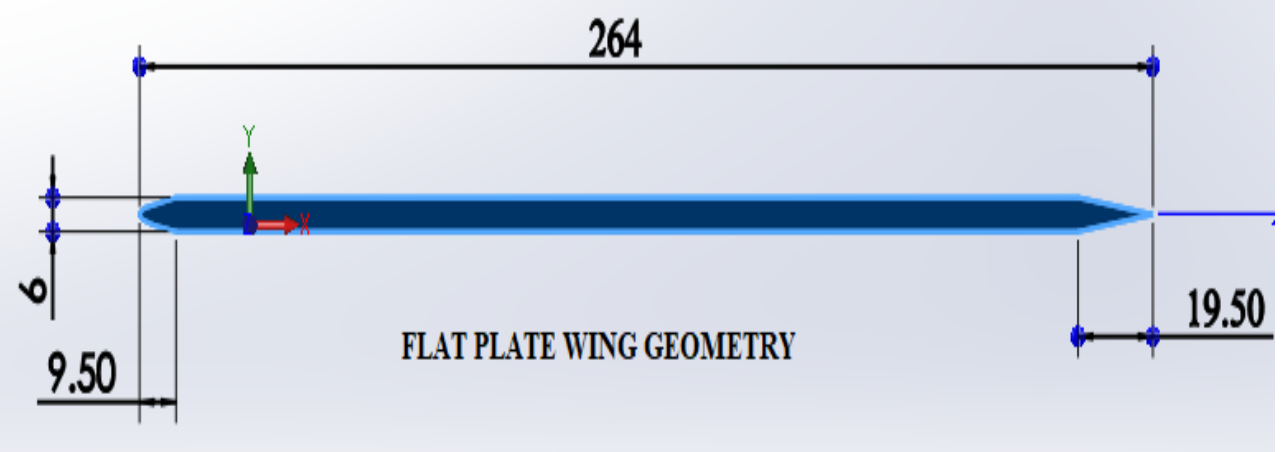

FLAT PLATE WING-3D VIEW

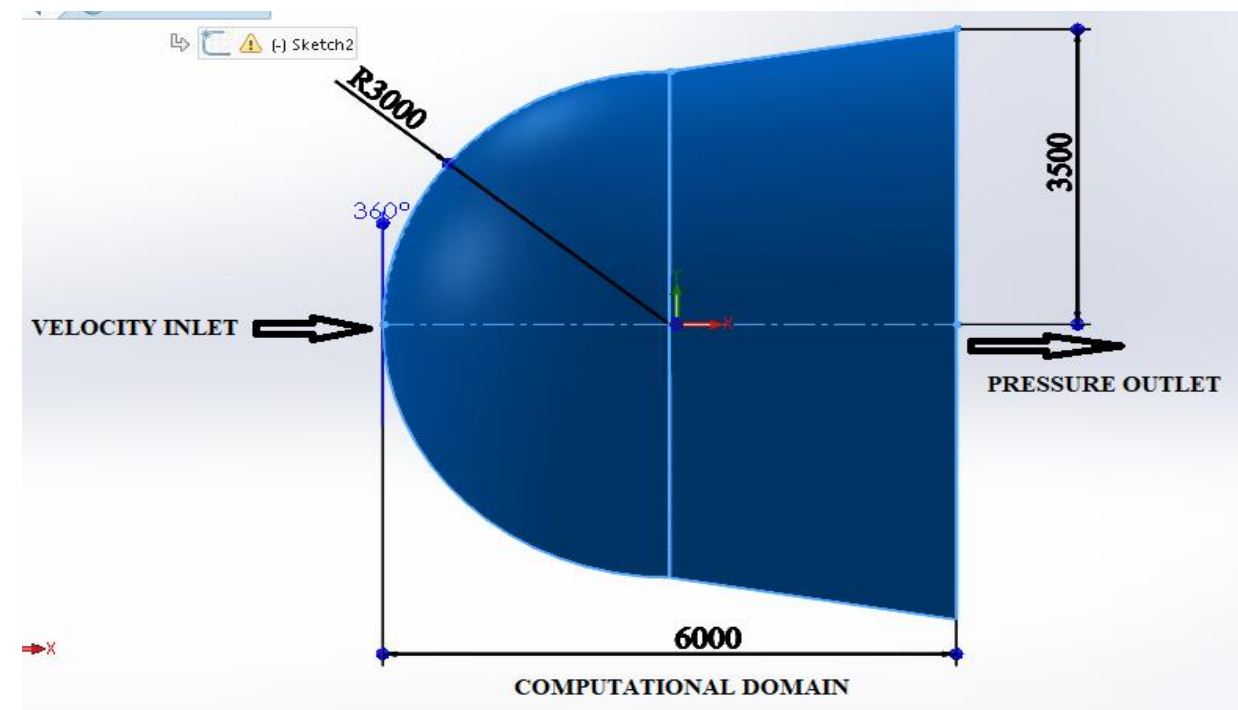

Figure 1. Model and computational domain description (All dimensions in $\mathrm{mm}$ ). 
Table 1

3D flat plate wing specification

\begin{tabular}{|l|l|l|}
\hline \multicolumn{3}{|c|}{ Model: 3D Flat plate wing } \\
\hline Chord (c) & 0.264 & $\mathrm{~m}$ \\
\hline Area (A) & 0.2122 & $\mathrm{~m}^{2}$ \\
\hline Span (b) & 0.804 & $\mathrm{~m}$ \\
\hline Aspect Ratio & 3 \\
\hline Reynolds number & $3 \times 10^{5}$ \\
\hline
\end{tabular}

\section{Mesh Details}

The three-dimensional viscous, incompressible flow over the flat plate wing was simulated in STAR CCM+. It is also used to generate the computational mesh of the flat plate wing as the pre-processor. This consist of several types of volume and surface mesh which are trimmed, tetrahedral and polyhedral. The polyhedral method (a volume with 14 faces) was chosen because of its ability to fit around the leading and trailing edges of the grid. Aerodynamic data can be achieved near wind tunnel experiment using unstructured polyhedral meshing with steady-state RANS (Reynolds-Averaged Navier-Stokes) approach and K-Omega SST turbulence model (Sagmo et al., 2016, Bui, 2016, Garcia et al., 2016, Shankara and Snyder, 2012, Narayana et al., 2005). An unstructured 3D mesh was generated for the flat plate wing in the computational domain. Approximately 15,00,000 mesh count was used in the polyhedral elements. There is an additional benefit of using the polyhedral meshing because it is computationally more efficient compared to another type of mesh. Figure 2 illustrates the surface and volume mesh and plane section and mesh near the LE and TE. The prism layer is selected with $0.032 \mathrm{Cref}$ thickness, and a total number of 12 layers is used to capture the flow near the wall. In Figure 2, the boundary layer mesh has been shown for a closer view. Table 2 shows the main meshing parameters which are used in the simulation. 
Table 2

\section{Mesh Parameters}

\begin{tabular}{|l|l|}
\hline Number of Cells & $4.1 \mathrm{M}$ \\
\hline Number of Surface Faces & $26.4 \mathrm{M}$ \\
\hline Target Prism Layer Height & $0.032 \mathrm{Cref}$ \\
\hline Number of Prism Layers & 12 \\
\hline Number of Vertices & $21.6 \mathrm{M}$ \\
\hline
\end{tabular}

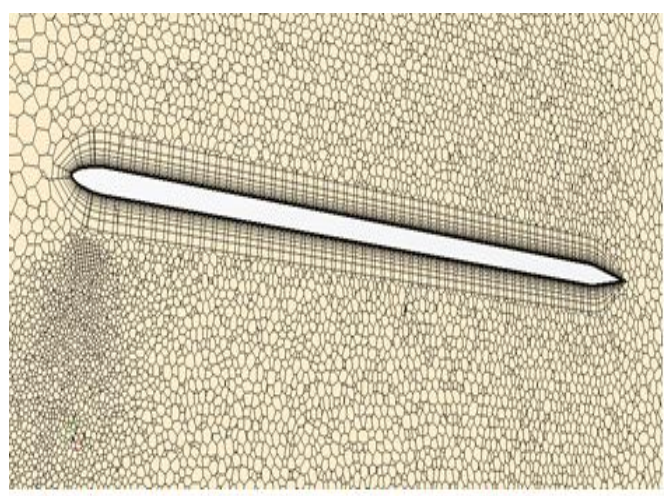

3D flat plate wing Volume Mesh with prism layer

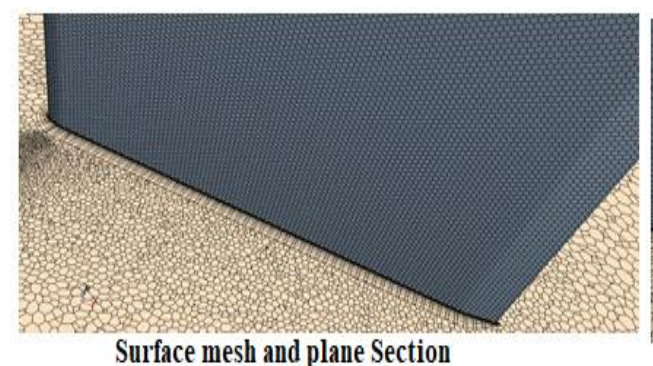

Surface mesh and plane Section

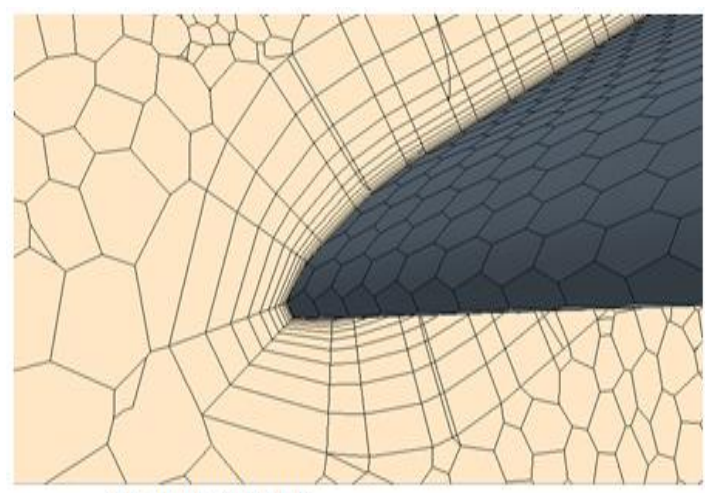

Mesh near the LE

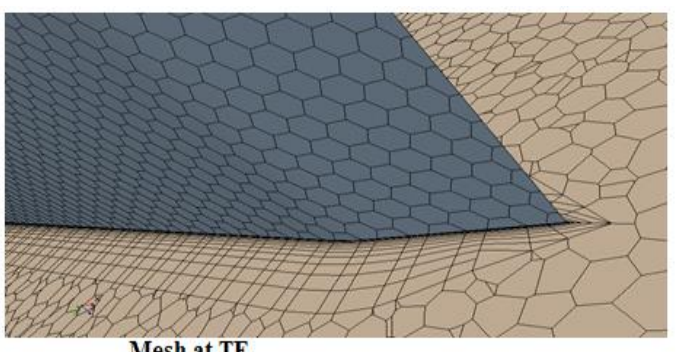

Mesh at TE

Figure 2. Flat plate wing meshing

\section{Simulation physics}

To set up an incompressible aerodynamics model using the steady-state RANS approach, the physics model details are presented in Table 3. The SpalartAllmaras turbulence flow model was used. The Spalart-Allmaras turbulence model can be used in cases of streamlined geometries without large base separation regions. This model works best for attached boundary layers or mildly separated flows (that is, flow past a wing at or below stall). This model is specially designed 
for aerospace applications in the wall boundary flows, which is mainly used to properly solve the areas of the boundary layer that is affected by viscosity and has good convergence toward solid wall turbulent flow. It has the benefit of being readily employed in an unstructured CFD solver. It has become a popular model in unstructured CFD methods in the aerospace industry (Baldwin and Lomax, 1978, Johnson and King, 1985). Spalart-Allmaras and Realizable k-epsilon Turbulence models showed good results for 2D and 3D wing models at low Reynolds number (Sagmo et al., 2016)

Table 3

Physics setup

\begin{tabular}{|l|l|}
\hline Group Box & Model \\
\hline Space & Three Dimensional \\
\hline Time & Steady \\
\hline Material & Gas-Air \\
\hline Flow & Segregated Flow \\
\hline Equation of State & Constant Density \\
\hline Viscous Regime & Turbulent \\
\hline \multirow{3}{*}{ Turbulence } & $\begin{array}{l}\text { Reynolds-Averaged } \\
\text { Navier-Stokes }\end{array}$ \\
\cline { 2 - 2 } & Spalart-Allmaras \\
\hline
\end{tabular}

\section{Results and Discussion}

Three-dimensional steady turbulent flow at constant density was selected, and no-slip wall boundary conditions are applied at the wing surface with velocity inlet and pressure outlet boundary conditions. Flat plate wing simulations were performed and ran for 1,500 to 2,000-time iteration (steps) for each case of study. The quarter chord point on the wing was used as the moment reference point and the point of rotation. One case simulation run time was between 8 to 20 hours.

After 1500-time iterations, the aerodynamic coefficients of flat plate wing reached a constant value for angles of attack from $-10^{\circ}$ to $10^{\circ}$. Beyond an angle of attack of $\pm 10^{\circ}$, small variations in yaw moment coefficient $\left(C_{N}\right)$, roll moment coefficient $\left(C_{l}\right)$ and side force coefficient $\left(C_{Y}\right)$ are present even after 2500 iterations. 
In the next sections, firstly, the validation results are discussed. Six component results (effect of pitch angle) are discussed when only the pitch angle $(\alpha)$ is varying. The roll $(\beta)$ and yaw angles $(\gamma)$ are zero for this part. Six components result for cases of yaw, roll and the combination of all three angles (effect of yaw, roll and pitch angles) will also be presented. Finally, flat plate wing aerodynamic stability derivatives in the linear portions of the graphs for all aerodynamic components are presented.

\section{Validation of Simulation Data}

For validation of the CFD solution, a case study was done on the rectangular flat-plate AR-3 wing at a Reynolds number of 80,000 . The $C_{L}, C_{D}$, and $C_{M}$ results from the CFD simulation are plotted in Figs. $3(\mathrm{a} \& \mathrm{~b})$ and 4 with the experimental data for the same wing at the same Re available in the open literature (Ananda et al., 2015, Pelletier and Mueller, 2000, Shields and Mohseni, 2012). The CFD simulation results agree quite well with the experimental values.

The flat plate wing experimental data by Ananda et al., 2015, was obtained using a UIUCLRN-FB three-component wind tunnel force balance at Re 80,000. The differences between the AR-3 wing tested with the UIUCLRN-FB (Ananda et al., 2015) and the wing tested by (Pelletier and Mueller, 2000 and Shields and Mohseni, 2012), is that, Ananda used a wing with $4.3 \%$ thickness-to-chord ratio and 10-to-1 elliptical trailing edge thickness ratio compared to $2.6 \%$ and 5-to-1 ratios in the flat plate wing used by Pelletier and Mueller, 2000 and Shields and Mohseni, 2012 respectively. Lift, drag, and pitching moment comparison results are shown in the Figs. 3 (a \& b) and 4.

The lift and drag coefficients plotted in Figure 3(a) show close agreement between the CFD results [see Figure 3(a)] and the experimental data from (Ananda et al., 2015, Pelletier and Mueller, 2000, Shields and Mohseni, 2012). The slight differences found near the stall angle of attack and maximum lift coefficient $\left(C_{L \max }\right)$ may be because of the differences in the model's geometry and mesh design. Similarly, $C_{D}$ [Figure3(b)] shows good agreement with the experimental results. The minimum drag coefficient $\left(C_{D \text { min }}\right)$ from (CFD data $\&$ Ananda et al., 2015) are also found to be within the expected minimum drag range for a theoretical flat-plate wing at the same Reynolds numbers. The CFD data and the experimental data of Shields and Mohseni, 2012, show a slight disagreement. The $\mathrm{C}_{M}$ versus $\alpha$ is shown and validated in Figure 4 with data from (Ananda et al., 2015, Pelletier and Mueller, 2000, Shields and Mohseni, 2012). These results show slight differences that can be attributed to the geometry and mesh variations, including the differences in the three wind tunnels and test models as also suggested by Shields and Mohseni, 2012. 
The pitching moment $\left(C_{M}\right.$ is measured at the quarter chord from the leading edge of the wing) results suggest that although the moment is approximately close to zero for low angles of attack as shown in Figure 4, there is a variation in $C_{M}$ as a function of the angle of attack. Figs. $3(\mathrm{a} \& \mathrm{~b})$ and 4 , illustrate the results of the simulations of the $C_{L}, C_{D}$, and $C_{M}$ for a Reynolds number 80,000 and all data is reproduced here to illustrate the effectiveness of STAR CCM+ as a CFD tool as its results are validated with available experimental data for the flat plate wing of AR 3.
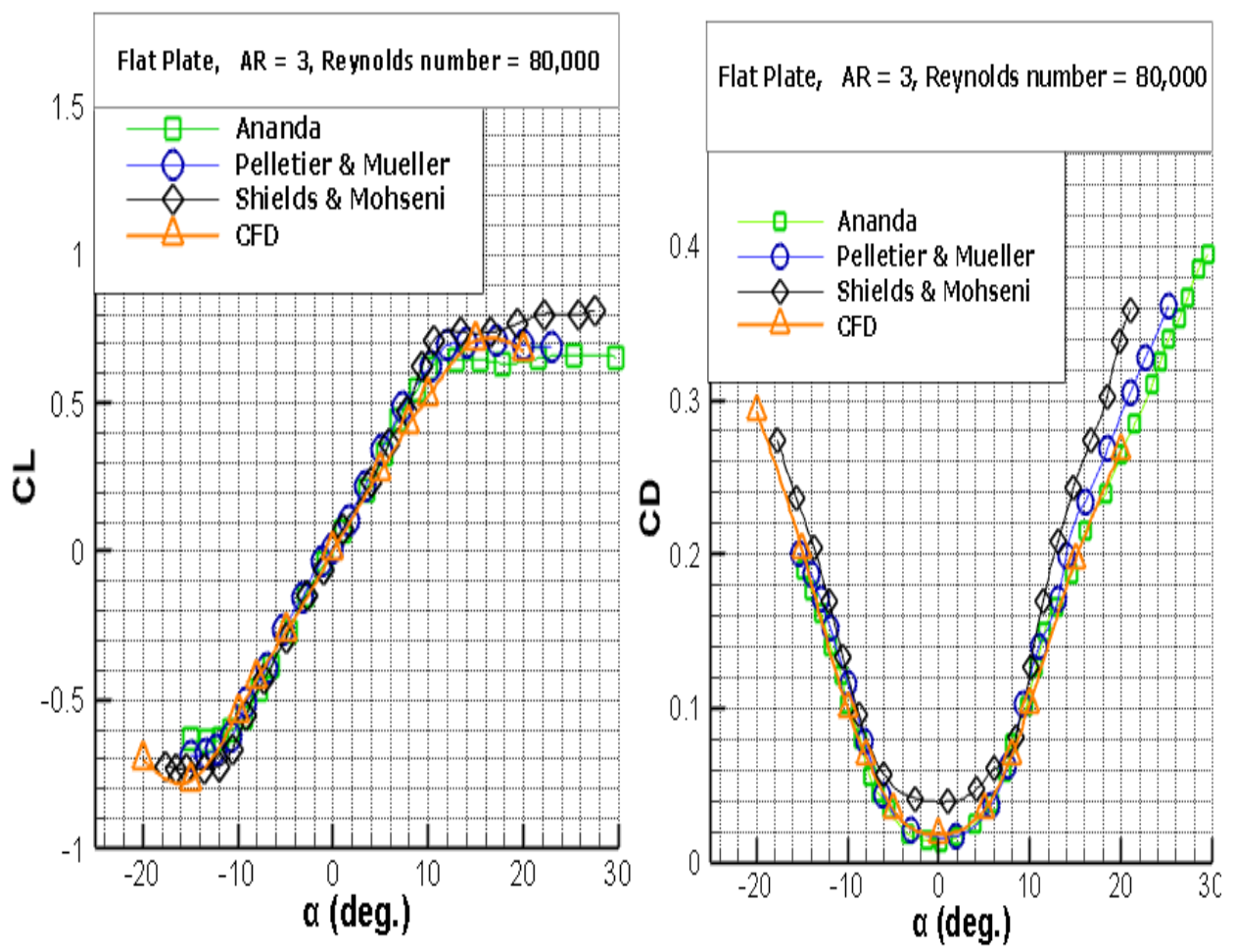

Figure 3. (a) Variation on lift coefficient and (b) drag coefficient with aoa 


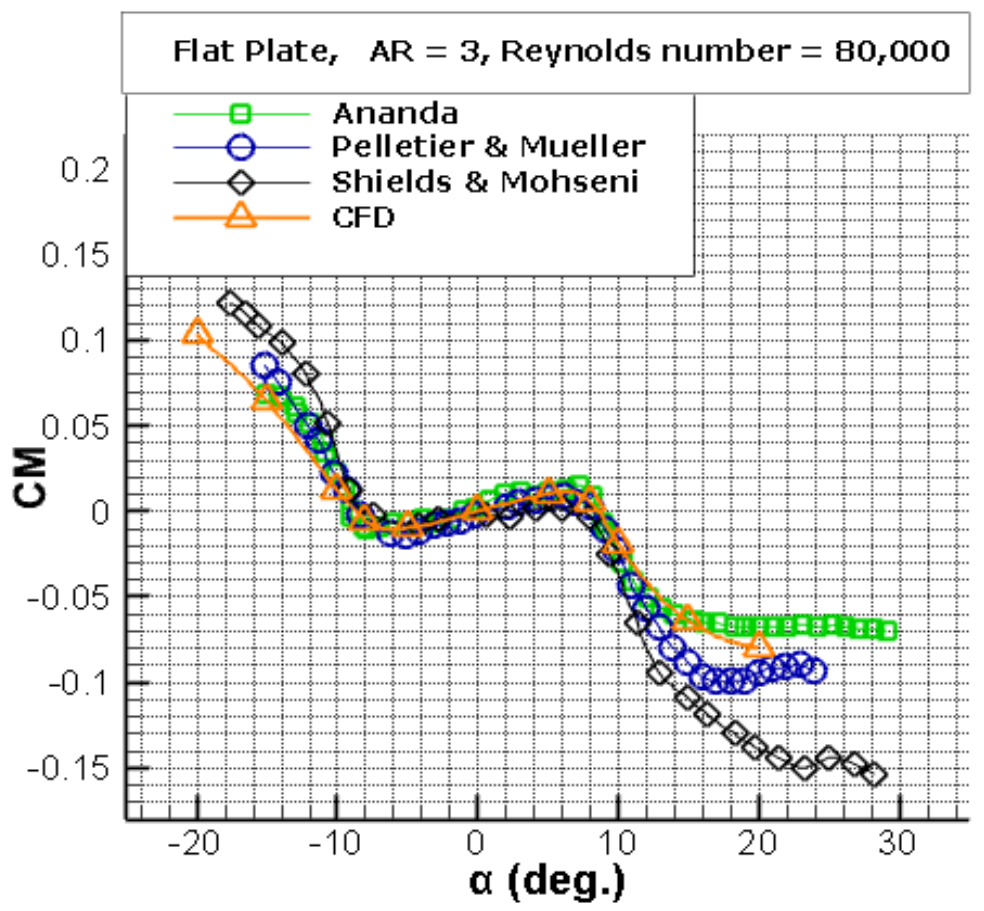

Figure 4. Variation of pitching moment coefficient with aoa

\section{Effect of Pitch Angle}

This section of the paper describes the behavior of the six aerodynamic force and moment components $\left(C_{L}, C_{D}, C_{M}, C_{N}, C_{l} \& C_{Y}\right)$ of a flat plate $3 D$ wing at a Reynolds number of $3 \times 10^{5}$ with respect to variations in the angle of pitch. The important characteristics discussed in this case relates to the maximum lift coefficient and the lift curve slope. The angle of attack (pitch angle) was varied from $-20^{0}$ to $25^{0}$. to identify post-stall effects of the flat-plate wing.

Lift, drag, and moment curves of the flat-plate wing are shown in Figs. 5 (a $\& b)$ and 6(a). The $C_{L}$ max for the flat plate wing was found be in the range of 0.67 to 0.7 at an angle of attack around $15^{\circ}$. Before stall, the quarter-chord $C_{M}$ was observed to be small for flat plate wing. In the post-stall regions, large negative $\mathrm{C}_{\mathrm{M}}$ was found with larger magnitude [see Figure6(a)]. In the post-stall region, $\mathrm{C}_{\mathrm{L}}$ and $\mathrm{C}_{\mathrm{M}}$ were found to be slightly constant over the range of angles of attack tested (up to $25^{\circ}$ ). As shown in Figure $5(\mathrm{~b})$, The $\mathrm{C}_{\mathrm{D}}$ min values are estimated to be approximately between 0.01 to 0.02 . 
$\mathrm{C}_{\mathrm{N}}, \mathrm{C}_{\mathrm{l}}$, and $\mathrm{C}_{\mathrm{Y}}$, have perhaps not been previously reported for a flat plate wing in the open literature. They are important factors in stability and control (Hull, 2007). As shown in Figure 6(b), The side force coefficient $C_{Y}$ was mostly constant with slight variations in the range of angle of attack from $-10^{\circ}$ to $25^{0}$, was consistently close to zero. Some variation is found in $\mathrm{C}_{Y}$ at angles of attack below $-10^{0}$.

The rolling moment $\mathrm{C}_{\mathrm{l}}$ is plotted in Figure 7(a) for angles of attack from $-10^{0}$ to $10^{0}$. The value of the $C_{l}$ was found approximately to be nearly zero $( \pm 0.00005)$ with a slight increment for the range of angle of attack $-8^{0}$ to $8^{0}$. In contrast, a negative graph (value lying between -0.0175 to 0 for up to $9^{0}$ angle of attack) was reported by Abe, for roll moment coefficient at 6800 Reynolds number. The computed $C_{l}$ data converge to the values plotted for the range of angle of attack from $-10^{0}$ to $10^{0}$ (Pre-stall regions). Beyond this range of angle of attack (Post stall regions), the $\mathrm{C}_{1}$ data did not converge, and fluctuations were observed during STAR CCM+ simulation. Hence only the range from $-10^{\circ}$ to $10^{\circ}$, rolling moment coefficient data are plotted here. This may be because of initiation of lift stall and start-up of flow separation. Similar behavior is observed for the yawing moment $\mathrm{C}_{\mathrm{N}}$.

Figure 7(b), describes the variation of the rolling moment $C_{N}$ vs. $\alpha$ for the flat plate wing. The $\mathrm{C}_{\mathrm{N}}$ was moderately variable but is not appreciably different from zero.
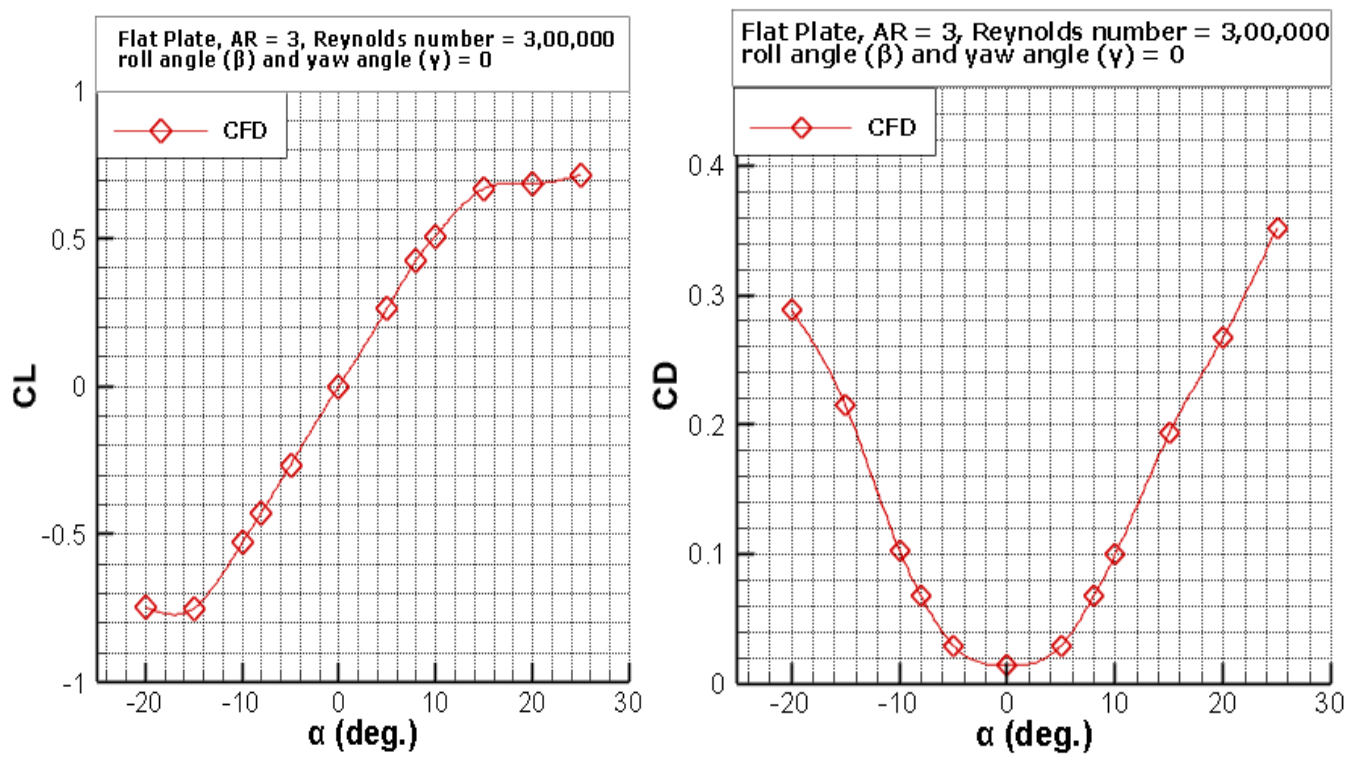

Figure 5. Variation of (a) lift and (b) drag with angle of attack 

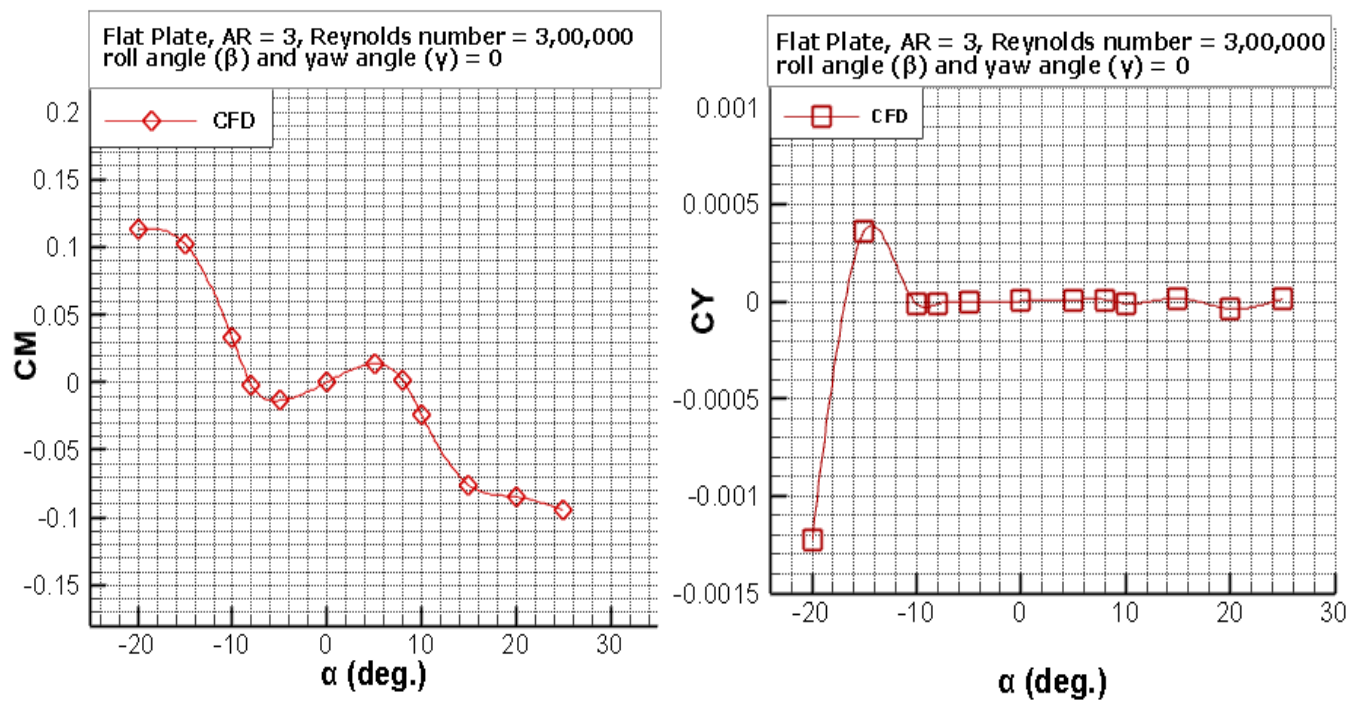

Figure 6. Variation of (a) pitching moment and (b) side force with angle of attack
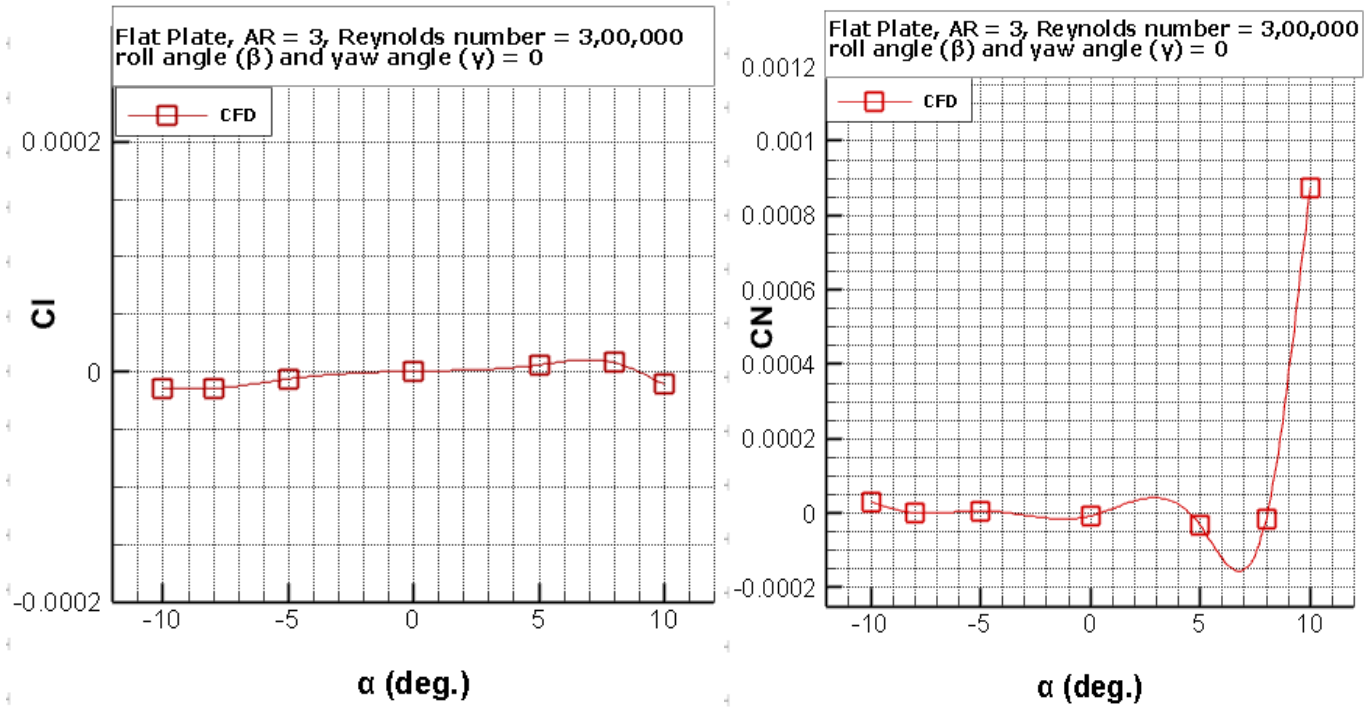

Figure 7. Variation of (a) roll moment and (b) yaw moment with angle of attack

\section{Effect of Yaw Angle}

This section discusses the effect of the variation in the yaw angle on the aerodynamic coefficients obtained from CFD simulation of the straight flat-plate $3 \mathrm{D}$ wing. Figures 8 to 10 describe the effect of yaw $(\gamma)$ from $-5^{0}$ to $20^{0}$ at $5^{0}$ intervals at constant values of the pitch angle (angle of attack) on the aerodynamic coefficients $\left(C_{L}, C_{D}, C_{M}, C_{N}, C_{l}, C_{Y}\right)$ of the flat plate wing. The pitch angle was 
varied from $0^{0}$ to $15^{0}$ at $5^{0}$ intervals at a Reynolds number of $3 \times 10^{5}$. The roll angle is set to zero.

Figure 8(a) shows the variation in the lift coefficient $\mathrm{C}_{\mathrm{L}}$ of the flat plate wing as a function of yaw angle for constant angles of attack (pitch angle) of $0^{0}, 5^{0}$, $10^{0}$ and $15^{0}$. The effect of yaw angle combined with pitch is observed on $\mathrm{C}_{\mathrm{L}}$. There is no similarity in the trends in the lift coefficient $\mathrm{C}_{\mathrm{L}}$ for the selected pitch angle positions of the flat plate wing. At $0^{0}$ pitch angle, $\mathrm{C}_{\mathrm{L}}$ is close to zero for all yaw angles. At a pitch angle of $5^{0}, C_{L}$ is different from zero but almost constant. The significant effect of pitch and yaw angle on $\mathrm{C}_{\mathrm{L}}$ is observed when the pitch angles are $10^{\circ}$ and $15^{\circ} . \mathrm{C}_{\mathrm{L}}$ max is 0.523 at $15^{\circ}$ yaw angle for a pitch angle of $10^{\circ}$ and 0.824 at $5^{0}$ yaw angle for pitch angle $15^{\circ}$. The effect of both pitch and yaw is significant. The $\mathrm{C}_{\mathrm{L}}$ slopes are given in Table 3.

Figure $8(\mathrm{~b})$ shows the variation of the drag coefficient $C_{D}$ of the flat plate wing as a function of yaw angle for constant angles of attack (pitch angle) of $0^{0}$, $5^{0}, 10^{\circ}$, and $15^{\circ}$. The trend of $C_{D}$ is similar to the behavior of the lift coefficient for all pitch angles. In general, the drag coefficient remains constant for variations in the yaw angle for pitch angles $0^{\circ}$ to $10^{\circ}$. At a pitch angle of $15^{\circ}$, the lift coefficient fluctuates in a sinusoidal manner for yaw angles between $-5^{0}$ to $20^{\circ}$. The $C_{D}$ min is approximately 0.0135 and 0.088 when pitch angles are $0^{\circ}$ and $10^{\circ}$. The slopes of the curves are presented in Table 3.

Figure 9(a) describes the variation of the pitching moment $\mathrm{C}_{\mathrm{M}}$, with yaw angles at constant pitch angles from $0^{0}$ to $15^{0} . \mathrm{C}_{\mathrm{M}}$, at $0^{0}$ pitch angle, is almost zero for all yaw angles. For a pitch angle of $5^{0}$, the pitching moment is positive and remains so for all yaw angles. For pitch angles $10^{\circ}$, and $15^{\circ}$ the pitching moment $\mathrm{C}_{\mathrm{M}}$, changes sign and remains negative for all yaw angles below $17^{0}$. The pitching moment is positive again for higher yaw angles. There is considerable variation in the magnitude and slope of the pitching moment curve when the pitch angle is $15^{\circ}$.

The variation in the side force $C_{Y}$ with respect to the yaw angle is shown in Figure 9(b) for several positive pitch angles (angle of attack). $C_{Y}$ is nearly zero for pitch angles $0^{\circ}$ and $5^{\circ}$. At pitch angles of $10^{\circ}$ and $15^{\circ}$, the behavior is markedly different. The magnitude of the side force is small, but the slope changes considerably. From the plots, it can be observed that side force values have changed from approximately from 0 (at $0^{0}$ yaw angle) to 0.029 (at $20^{\circ}$ yaw angle) when pitch angle is $10^{\circ}$ and 0 (at $0^{\circ}$ yaw angle) to 0.042 (at $20^{\circ}$ yaw angle) when pitch angle is $15^{0}$. In conclusion, pitch angle plays a role in the variation in the side force $C_{Y}$, but when the yaw angle changes with pitch angle, it is observed that the side force, $\mathrm{C}_{\mathrm{Y}}$ also depends on the yaw angle. 
Figure 10(a) shows roll moment coefficient vs. yaw angle plots for some positive pitch angles (angle of attack). The magnitude and the slope of the rolling moment curve increases as the pitch and the yaw angles increase. The rolling moment being zero for zero pitch angle.

The variation in the yawing moment $\mathrm{C}_{\mathrm{N}}$ as a function of the yaw angle can be seen in Figure10(b) for several fixed angles of attack. The yawing moment $\mathrm{C}_{\mathrm{N}}$ decreases when yaw angle increases for all pitch angles. For almost all yaw angles the yawing moment curves have negative slopes. Although in terms of magnitude, the yawing moment coefficient is small. The negative $C_{N}$ slopes are computed and shown in Table 3.
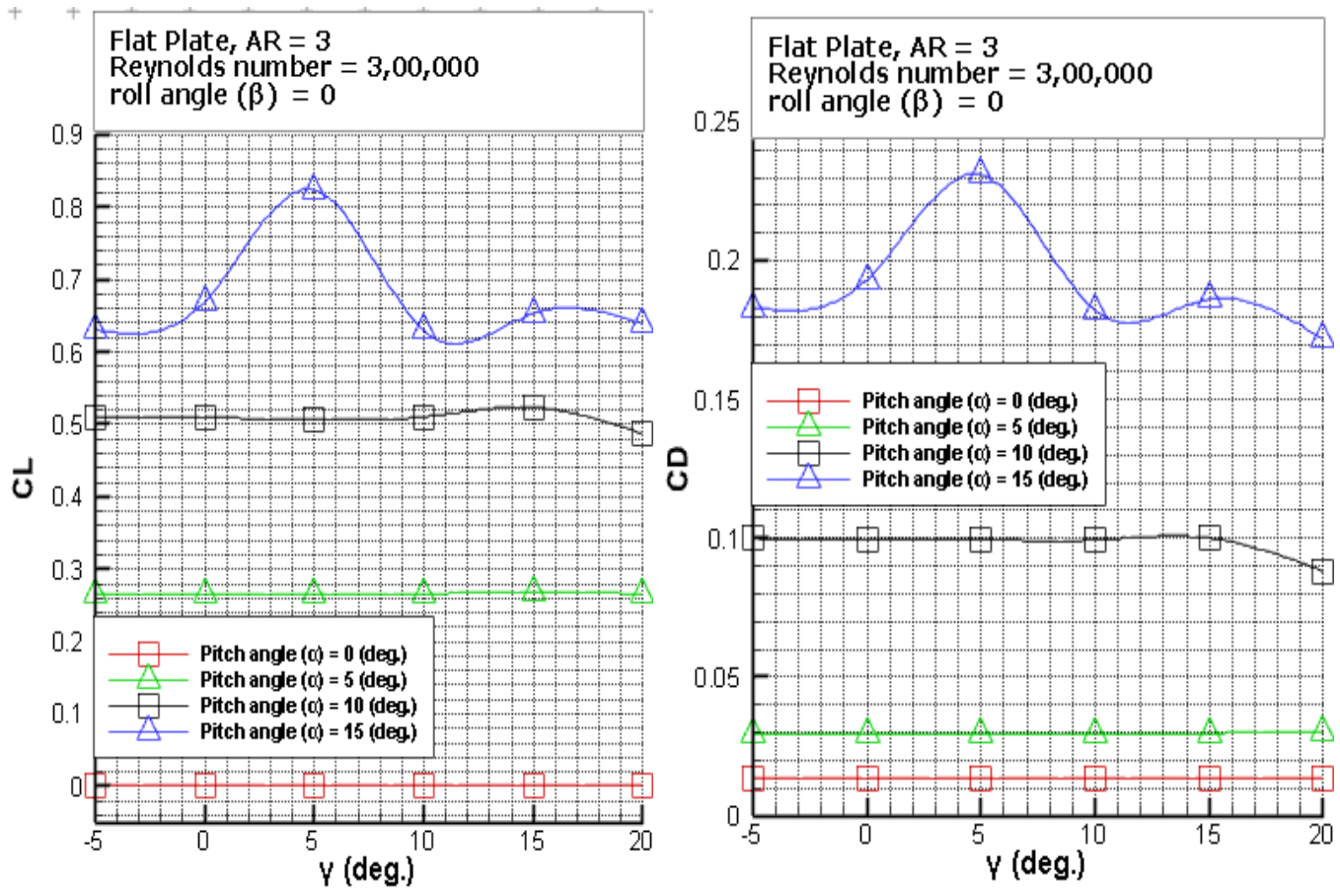

Figure 8.Variation of (a) Lift and (b) Drag of flat plate wing as a function of yaw angle for several pitch angles 
International Journal of Aviation, Aeronautics, and Aerospace, Vol. 5 [2018], Iss. 1, Art. 8
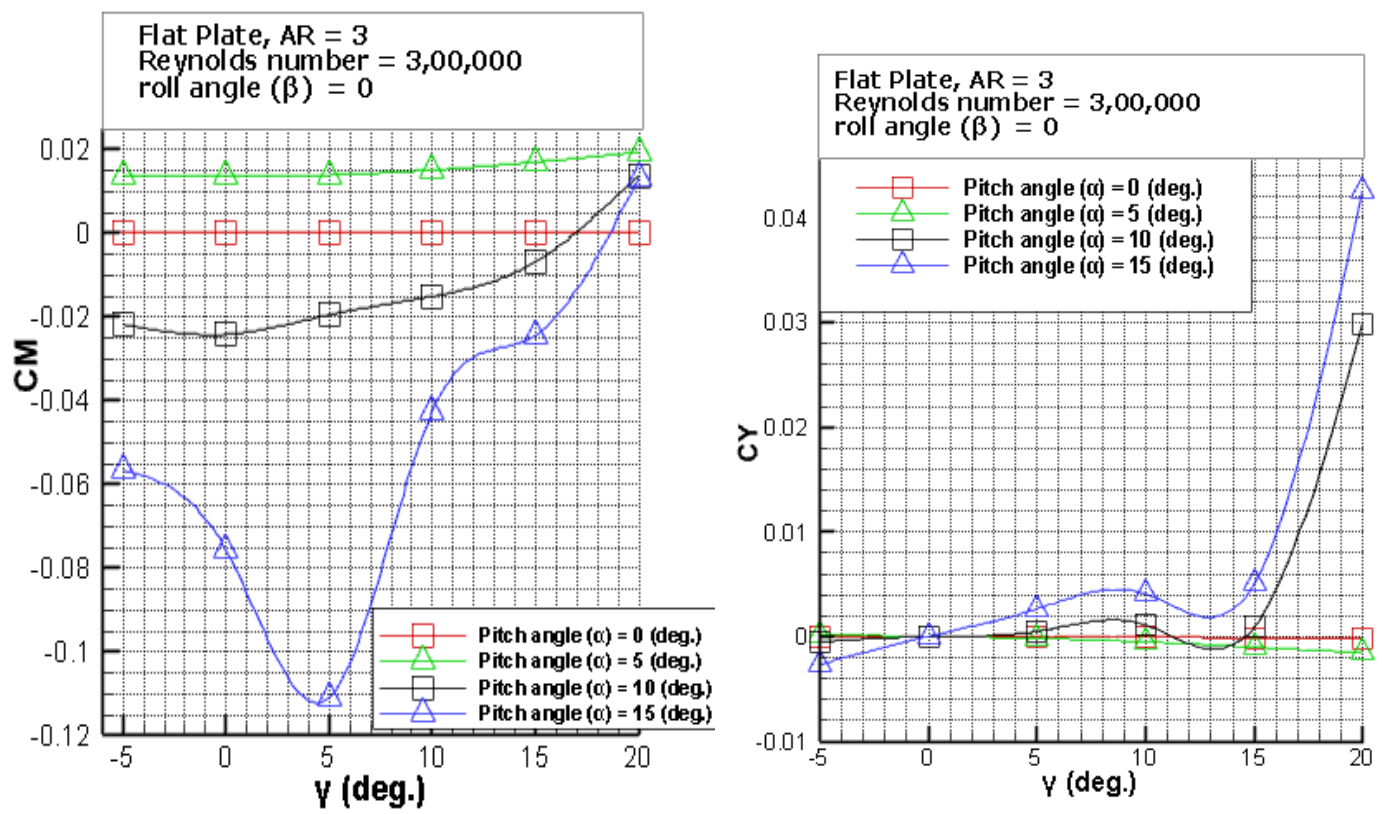

Figure 9. Variation of (a) Pitching moment and (b) Side force of flat plate wing as a function of yaw angle for several pitch angles
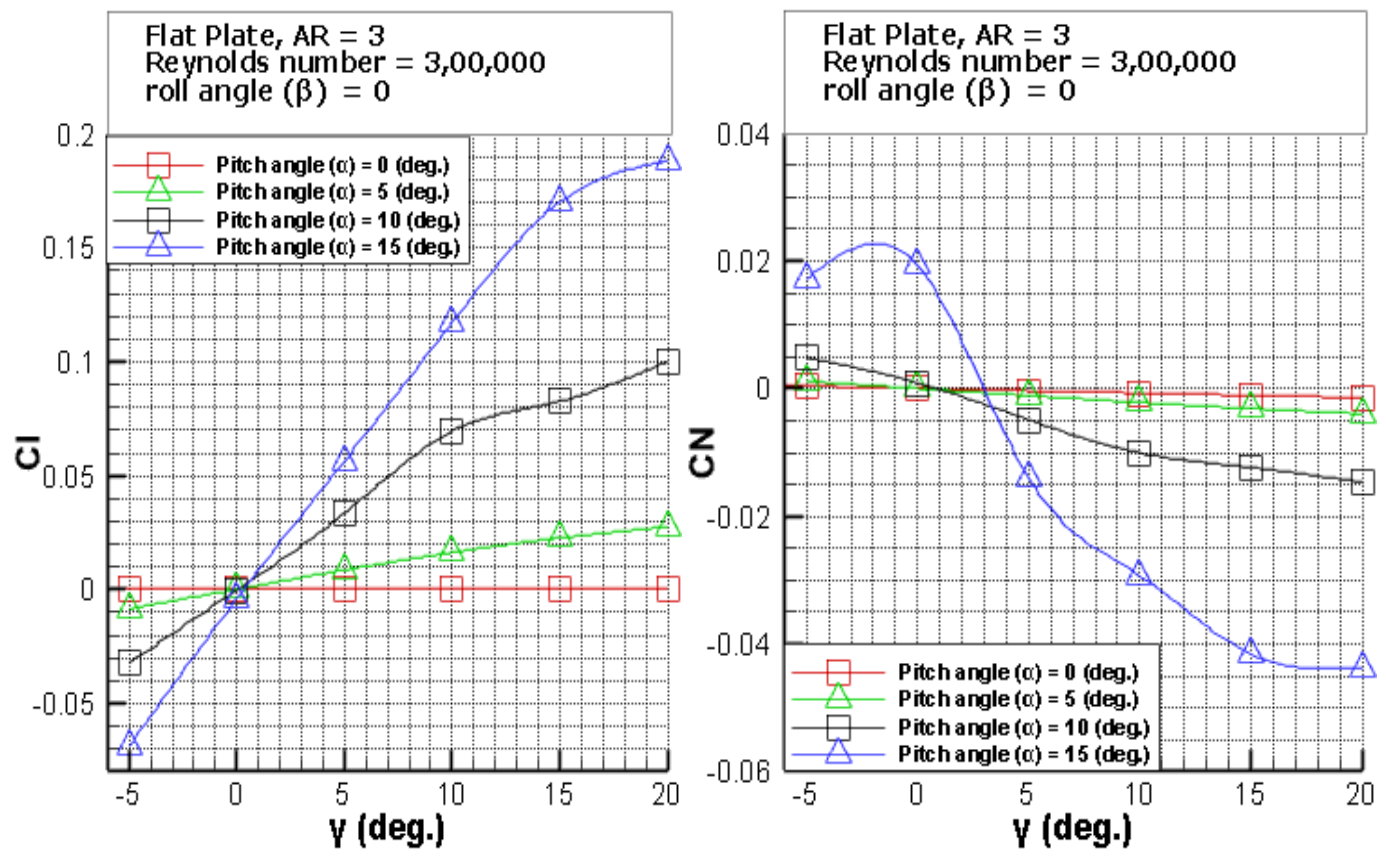

Figure 10. Variation of (a) Roll and (b) Yaw moment of flat plate wing as a function of yaw angle for several pitch angles 


\section{Effect of Roll Angle}

The roll angle plays an important part in aerodynamic properties which affect the aerodynamic coefficients and hence performance and stability. Figure 11(a) describes the variation in the lift coefficient $\mathrm{C}_{\mathrm{L}}$ as a function of the roll angle for different fixed pitch angles. The lift coefficient $C_{L}$ is zero for zero pitch angle and steadily increases as the pitch angle increases. For a fixed pitch angle, the variation in the lift coefficient as a function of the roll angle is small. A sinusoidal variation in the lift coefficient with roll angle is observed for a pitch angle of $15^{\circ}$.

The effect of roll angle can be seen on the drag coefficient $C_{D}$ in Figure 11(b) at different fixed pitch angles. The drag coefficient variation is very similar to the variation in the lift coefficient for all roll angles at various pitch angles.

The pitching moment coefficient versus roll angle plots are shown in Figure 12(a). The pitching moment $\mathrm{C}_{\mathrm{M}}$ is zero for a range of roll angles at a pitch angle of $0^{0}$. At pitch angle of $5^{0}$, the pitching moment is positive for all yaw angles but with a slightly negative slope. At pitch angles of $10^{\circ}$ and $15^{\circ}$, the pitching moment is negative for all roll angles. At these pitch angles, the pitching moment curve has a sinusoidal behavior as the yaw angle is varied.

Figure 12(b) shows the behavior of the side force coefficient versus roll angle for several fixed angles of attack (pitch angle). At zero pitch angle, the side force is zero for all roll angles. The side force coefficient varies almost linearly with a negative slope for all non-zero positive pitch angles

The rolling moment coefficient $\mathrm{C}_{1}$ versus roll angle graphs are shown in Figure 13(a) for pitch angles $0^{0}, 5^{0}, 10^{\circ}$ and $15^{\circ}$. The rolling moment is approximately near zero with slight fluctuation when pitch angle is $0^{0}$. At higher values of fixed pitch angles, the rolling moment versus roll angle curves tend to become increasingly negative in slope and magnitude. The computed $C_{l}$ slopes are shown in Table 3.

Figure 13(b) describes the variation in yaw moment coefficient with roll angle at $0^{0}, 5^{0}, 10^{\circ}$ and $15^{0}$ pitch angles. The yaw moment coefficient $C_{N}$ is near zero for all roll angles when the pitch angle is zero. It varies linearly with the roll angle, with a positive slope for a pitch angle of $5^{0}$ and a negative slope for pitch angle $10^{\circ}$. At a pitch angle of $15^{\circ}$ the variation of the yawing moment with roll angle is sinusoidal. 

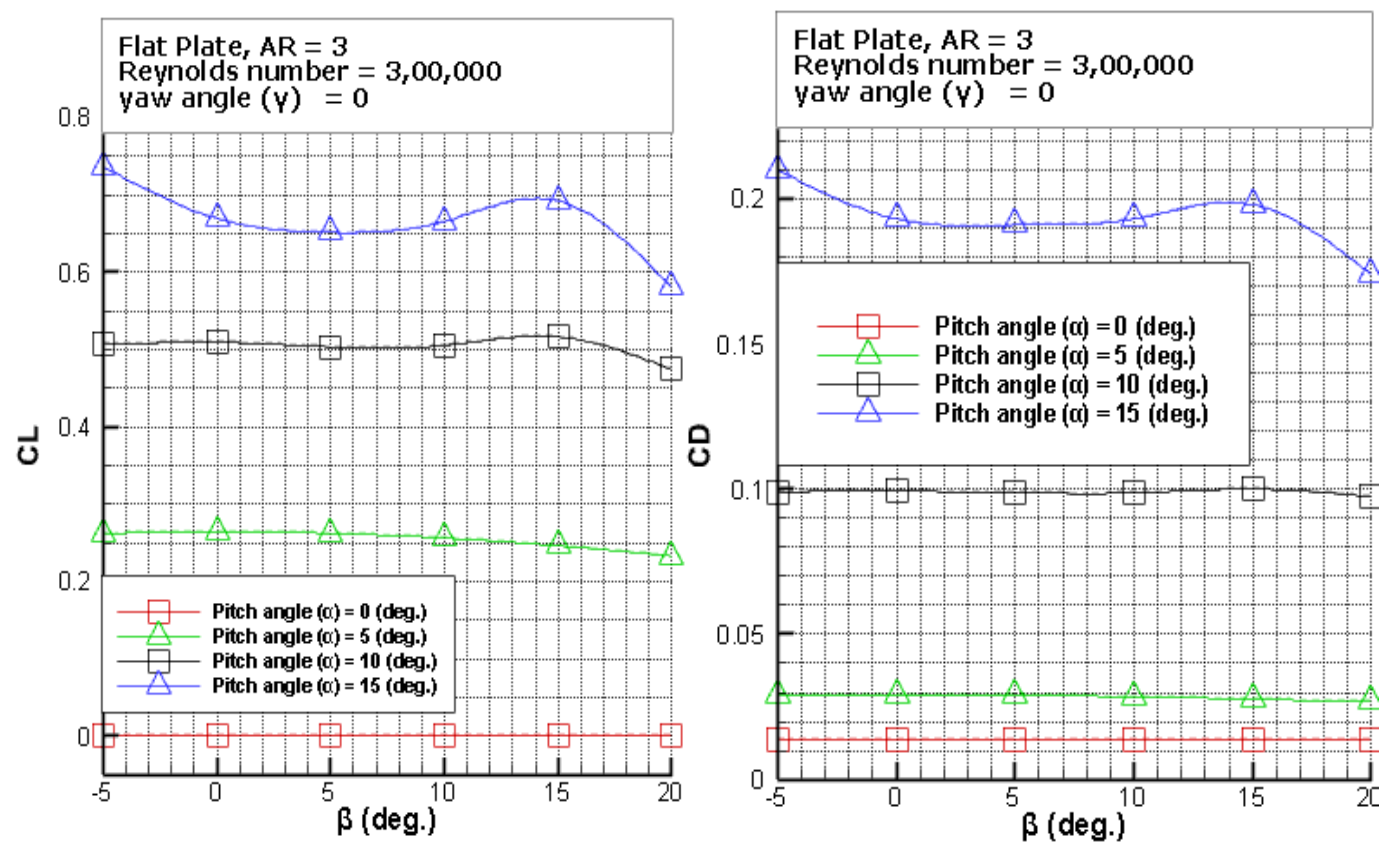

Figure 11. Variation of (a) Lift and (b) Drag of flat plate with as a function of roll angle for several pitch angles
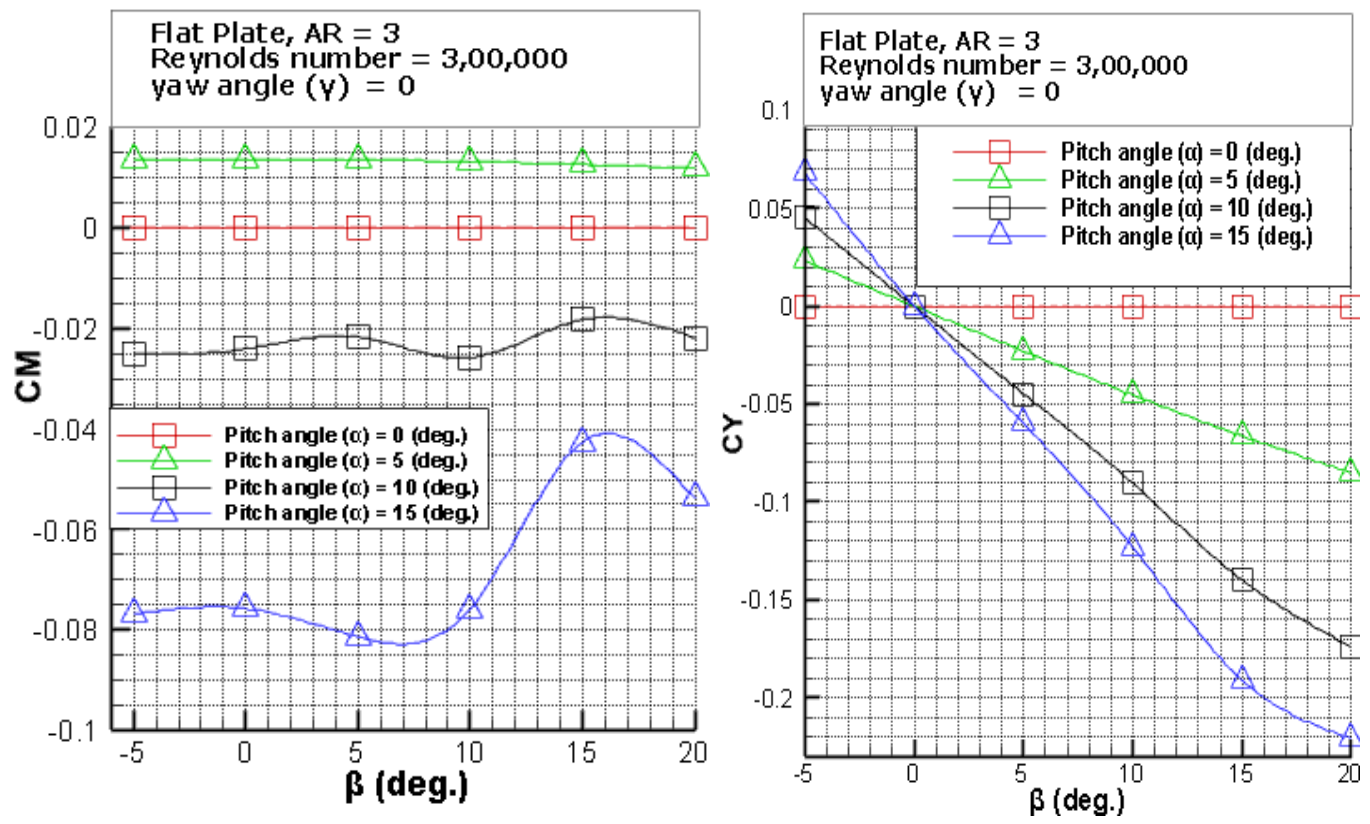

Figure 12. Variation of (a) Pitching moment and (b) Side force of flat plate with as a function of roll angle for several pitch angles 

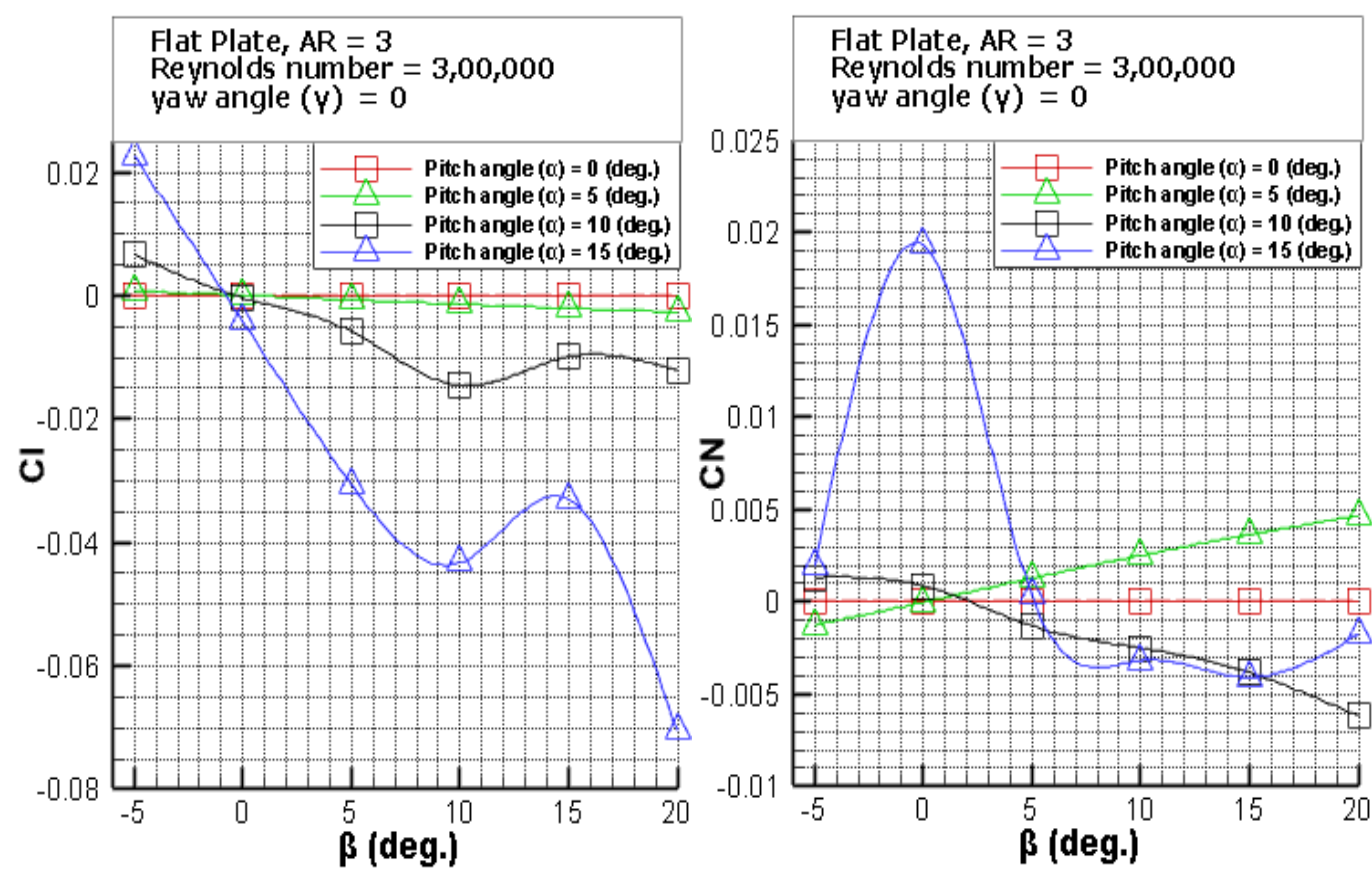

Figure 13. Variation of (a) Roll and (b) Yaw moment of flat plate with a function of roll angle for several pitch angles

\section{Effect of combination of all angles (Pitch, Roll, and Yaw)}

Figures 14 to 16, explain the impact of the combination of pitch, roll, and yaw angle variation on aerodynamic coefficients of a flat plate wing. The pitch and roll angles are held constant at $-5^{0}$ and $5^{0}$ while the yaw angle is varied from $-10^{0}$ to $10^{0}$ at $5^{0}$ intervals. The Reynolds number is $3 \times 10^{5}$.

Figure 14(a) shows lift coefficient $\mathrm{C}_{\mathrm{L}}$ variation of a flat plate as a function of yaw angle for pitch and roll angles of $5^{0}$ and $-5^{0}$. The $C_{L}$ slope is positive at pitch and roll angle $5^{0}$ with $\mathrm{C}_{\mathrm{L}}$ max around 0.319. A negative $\mathrm{C}_{\mathrm{L}}$ slope is observed when the position of the flat plate was at pitch and roll $-5^{0}$. The behavior at the positive and negative roll and pitch angles are mirror images, with $\mathrm{C}_{\mathrm{L}}$ max around 0.319 for roll and pitch angle of $-5^{0}$.

The drag coefficient $C_{D}$ vs. yaw angle graph is shown in Figure 14(b). There is an increasing trend in the drag coefficient with positive drag coefficient slope for both $5^{0}$ and $-5^{0}$. pitch and roll angles. The $C_{D}$ min is approximately 0.023 .

Figure 15(a) shows the variation of the pitching moment $C_{M}$ vs. yaw angle for pitch and roll angles of $5^{0}$ and $-5^{0}$. The pitching moment coefficient increases 
as the yaw angle increases for $5^{0}$ pitch and roll angle. The positive pitching moment coefficient slope found is around 0.000246 . When the flat plate position is at $-5^{0}$ pitch and roll angle, a negative trend is observed with negative values of the pitching moment. The pitching moment curve behavior at $-5^{0}$ (roll and pitch) is almost a mirror image of the behavior at $5^{0}$ (roll and pitch).

The side force coefficient behavior is found to be significant when all three angles of the wing change. In Figure 15(b), the side force coefficient $C_{Y}$ vs yaw angle for $5^{0}$ and $-5^{0}$ pitch and roll angles are plotted. At $5^{0}$ pitch and roll angles, values of $\mathrm{C}_{Y}$ are negative and nearly constant for all values of the yaw angle. The side force is of the same magnitude as the drag force. For a pitch and roll angle of $-5^{0}$ the side force coefficient remains nearly constant at negative yaw angles but increases to positive values for positive yaw.

Figure 16(a) shows the variation of the rolling moment $C_{1}$ vs. yaw angle for $5^{0}$ and $-5^{0}$ pitch and roll angles. The $C_{1}$ increases as yaw angle increases with a positive slope value of 0.0017 for $5^{0}$ pitch and roll angles position. When the position of flat plate wing is at $-5^{0}$ pitch and roll angles, $C_{l}$ decrease as yaw angle increases with a negative slope value -0.0018 .

The yaw moment coefficient $\mathrm{C}_{\mathrm{N}}$ variation with yaw angle for $5^{0}$ and $-5^{0}$ pitch and roll angles, is shown in figure $16(\mathrm{~b})$. The $\mathrm{C}_{\mathrm{N}}$ declines as yaw angle increases for both $5^{0}$ and $-5^{0}$ pitch and roll angles positions. Yaw moments coefficient negative slope value is around -0.00023 for both cases.

Table 3 shows the computed slopes in the linear portions of the graphs for all aerodynamic components $\left(C_{L}, C_{D}, C_{M}, C_{N}, C_{l}, C_{Y}\right)$. It was found that as pitch angle increases lift derivative increases in all cases. The highest slopes are observed for a pitch angle of $15^{0}$ for all cases. Lowest slopes are found at pitch angle $0^{0}$ for all cases. $\alpha, \beta$, and $\gamma$ are pitch, roll and yaw angles respectively (note: Please see appendix 2 for Table 3 ). 

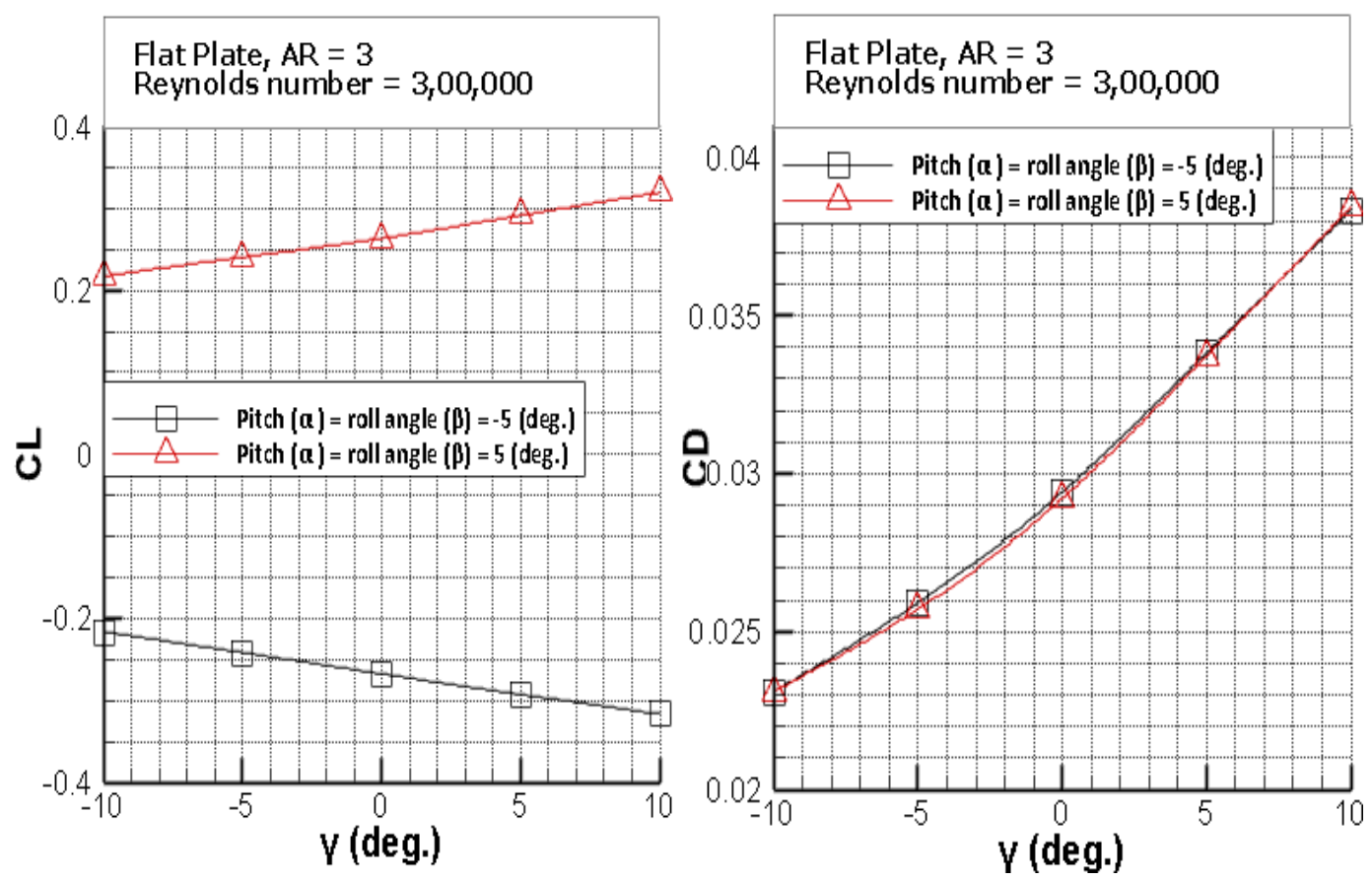

Figure 14. Variation of (a) Lift and (b) Drag variation of flat plate as a function of yaw angle for several pitch and roll angles
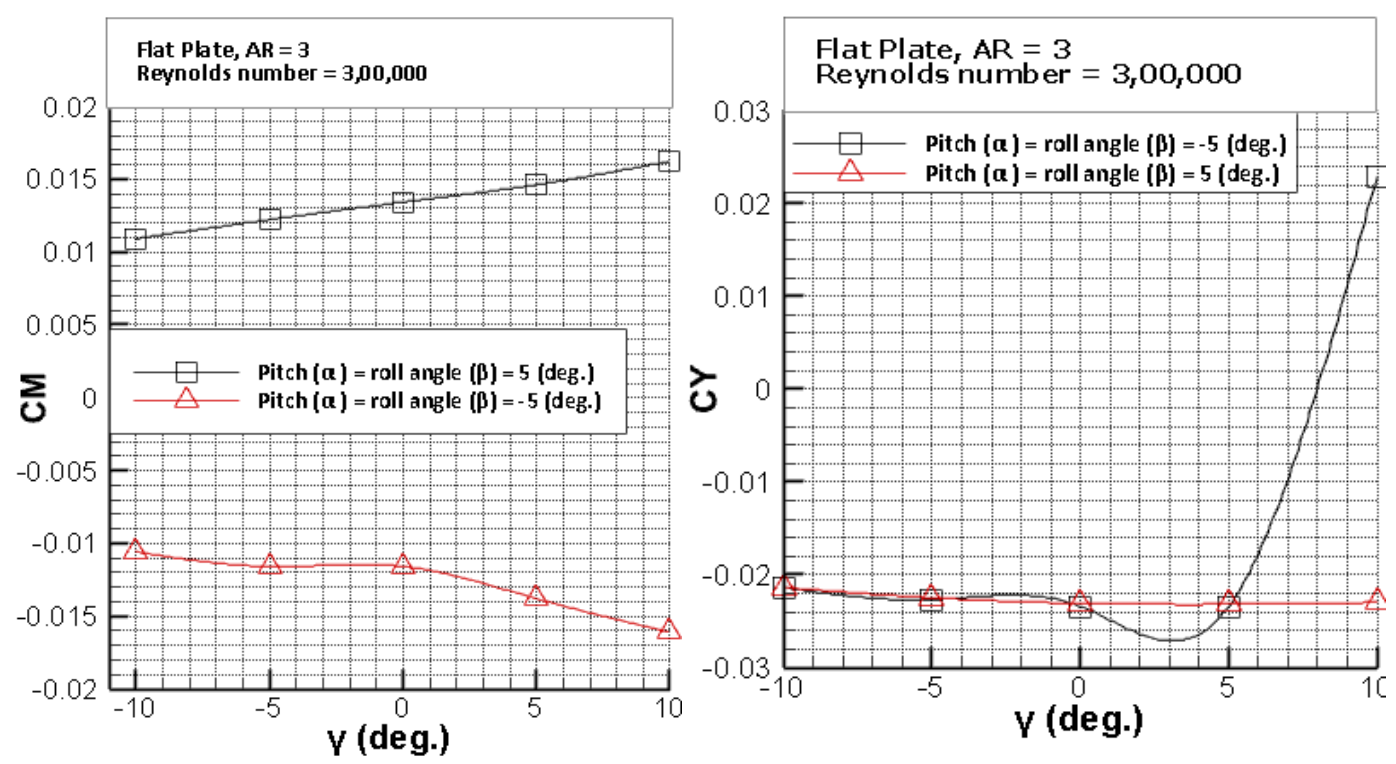

Figure 15. Variation of (a) Pitching moment and (b) Side force of flat plate as a function of yaw angle for several pitch and roll angles 

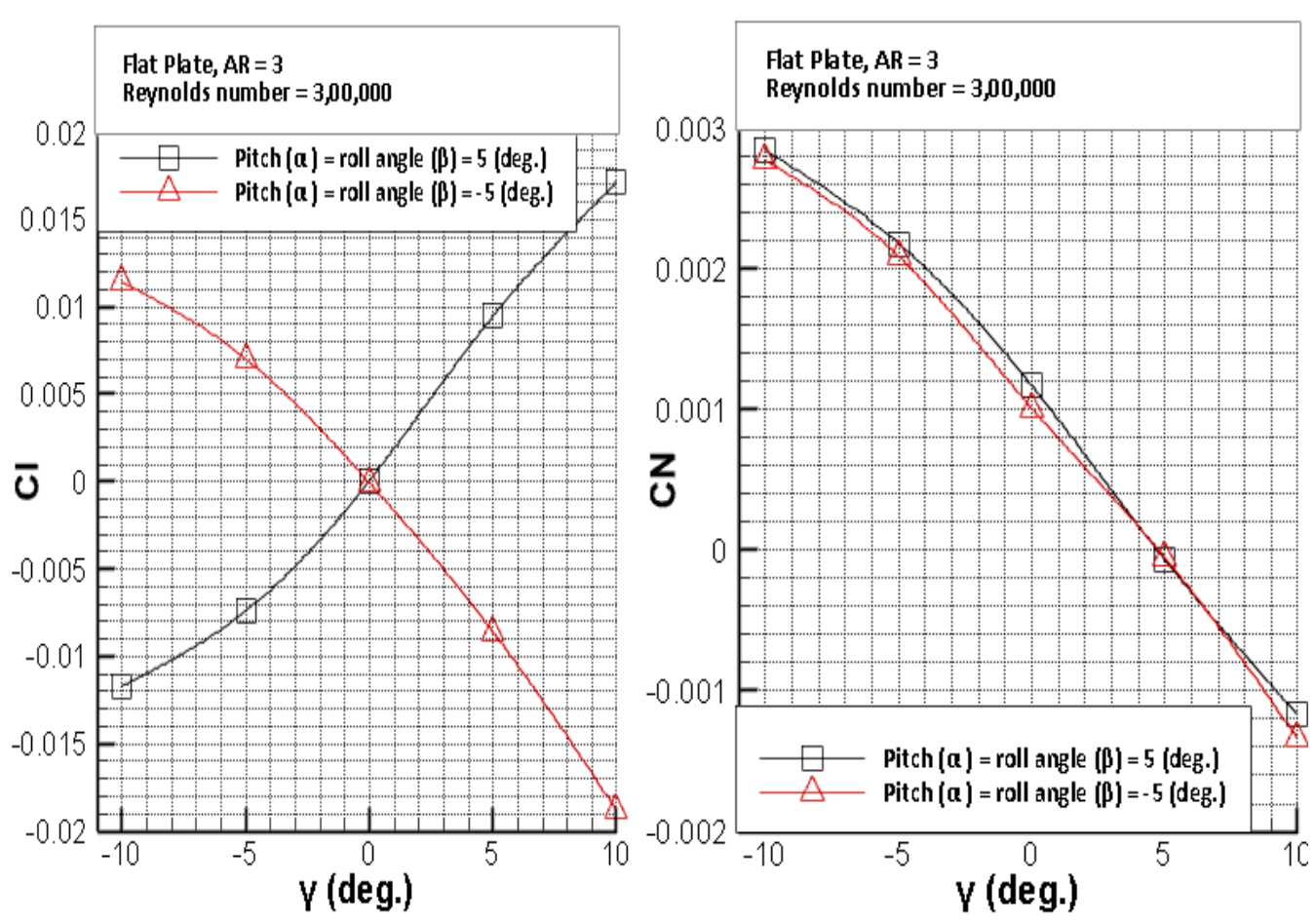

Figure 16. Variation of (a) Rolling and (b) Yaw moment of flat plate with a function of yaw angle for several pitch and roll angle

\section{Conclusion}

This paper presents an estimation of the six aerodynamic coefficients and their derivatives of a flat plate straight three-dimensional wing of aspect ratio 3 , at a Reynolds number of $3 \times 10^{5}$. The numerical simulation results have been validated with existing available experimental data $\left(C_{L}, C_{D}\right.$, and $\left.C_{M}\right)$. The computed data agrees well with benchmark results. They show that roll and yaw angle affect the aerodynamic coefficients of the wing along with the pitch angle. There is no doubt that pitch angle plays the most significant part. In case of pitch angle variation when yaw \& roll angle was zero, the side force, yawing moment and the roll moment were near zero. For zero roll angle, the effect of variation in the yaw angle is most significant on all aerodynamic coefficients only at pitch angles (angle of attack) greater than $10^{\circ}$. For zero yaw angle, the effect of variations in the roll angle is significant for pitch angles (angle of attack) greater than $10^{\circ}$. Significant effects on the magnitude and slope of the lift, pitching, and rolling moments and the side force was observed as a function of the yaw angle when pitch and roll angles were not zero. The drag and yaw moment magnitude and slopes are unaffected by changes in the yaw angle for a fixed pitch and roll angle. A Table of aerodynamic 
Malik et al.: SIMULATION OF A 3D WING

stability derivatives has been added. The derivatives are computed using linear approximations to the curves. 


\section{References}

Abe, C. (2003). Aerodynamic force and moment balance design, fabrication and testing for use in low Reynolds flow applications. Thesis. Rochester Institute of Technology. Retrieved from http://scholarworks.rit.edu/theses/5927.

Ananda, G. K., Sukumar, P. P., \& Selig, M. S. (2015). Measured aerodynamic characteristics of wings at low Reynolds numbers. Aerospace Science and Technology, 42, 392-406. https://doi.org/10.1016/j.ast.2014.11.016

Anderson, J. D (2007). Introduction to flight. New York, NY: McGraw-Hill.

Anderson, J. D., \& Wendt, J. (1995). Computational fluid dynamics (Vol. 206). New York, NY: McGraw-Hill.

Baldwin, B. S., \& Lomax, H. (1978). Thin layer approximation and algebraic model for separated turbulent flows (Vol. 257). American Institute of Aeronautics and Astronautic, AIAA 16TH AEROSPACE SCIENCES MEETING Huntsville, AL, January 16-18,1978.

Bui, T. T. (2016). Analysis of low-speed stall aerodynamics of a swept wing with seamless flaps. 34th AIAA Applied Aerodynamics Conference, AIAA AVIATION Forum, (AIAA 2016-3720). doi: https://doi.org/10.2514 /6.2016-3720.

Fail, R., Eyre, R. C. W., \& Lawford, J. A. (1959). Low-speed experiments on the wake characteristics of flat plates normal to an air stream. Retrieved from http://naca.central.cranfield.ac.uk/reports/ arc/rm/3120.pdf.

Garcia, J. A., Melton, J. E., Schuh, M., James, K. D., Long, K. R., Vicroy, D. D., ... \& Stremel, P. M. (2016). NASA ERA Integrated CFD for Wind Tunnel Testing of Hybrid Wing-Body Configuration. AIAA SciTec 2016. doi: https://doi.org/10.2514/6.2016-0262.

Hull, D. G. (2007). Fundamentals of airplane flight mechanics. New York, NY: Springer-Verlag. 
Johnson, D. A., \& King, L. S. (1985). A mathematically simple turbulence closure model for attached and separated turbulent boundary layers. AIAA journal, 23(11), 1684-1692. doi: https://doi.org/10.2514/3.9152.

Laitone, E. V. (1997). Wind tunnel tests of wings at Reynolds numbers below 70 000. Experiments in Fluids, 23(5), 405-409. doi: https://doi.org/10.1007 /s003480050

Mcgrath, B. E., Neuhart, D. H., Gatlin, G. M., \& Oneil, P. (1994). Low-speed longitudinal aerodynamic characteristics of a flat-plate planform model of an advanced fighter configuration. NASA-TM-109045,NAS 1.15:109045.

Mueller, T. J., \& DeLaurier, J. D. (2003). Aerodynamics of small vehicles. Annual Review of Fluid Mechanics, 35(1), 89-111. doi: 10.1146 /annurev.fluid.35.101101.161102

Narayana, P. A., \& Seetharamu, K. N. (2005). Engineering fluid mechanics. Harrow, UK: Alpha Science International, Ltd.

Ortiz, X., Rival, D., \& Wood, D. (2015). Forces and moments on flat plates of small aspect ratio with application to PV wind loads and small wind turbine blades. Energies, 8(4), 2438-2453. doi: 10.3390/en8042438.

Pelletier, A., \& Mueller, T. J. (2000). Low Reynolds number aerodynamics of low-aspect-ratio, thin/flat/cambered-plate wings. Journal of Aircraft, 37(5), 825-832. doi: https://doi.org/10.2514/2.2676.

Rumsey, C. L., Long, M., Stuever, R. A., \& Wayman, T. R. (2011). Summary of the first AIAA CFD high lift prediction workshop. Journal of Aircraft, 48(6), 2068-2079.

Sagmo, K. F., Bartl, J., \& Sætran, L. (2016). Numerical simulations of the NREL S826 airfoil. Journal of Physics: Conference Series, 753(8), 082036.

Shankara, P., \& Snyder, D. (2012). Numerical simulation of high lift trap wing using STAR-CCM+. AIAA, 2920, 2012. doi: 10.2514/6.2012-2920

Shields, M., \& Mohseni, K. (2012). Effects of sideslip on the aerodynamics of low-aspect-ratio low-Reynolds-number wings. AIAA journal, 50(1), 85-99. doi: $10.2514 / 1 . j 051151$ 
International Journal of Aviation, Aeronautics, and Aerospace, Vol. 5 [2018], Iss. 1, Art. 8

Sun, Q., \& Boyd, I. D. (2004). Flat-plate aerodynamics at very low Reynolds number. Journal of Fluid Mechanics, 502, 199-206. doi: 10.1017 /s0022112003007717. 


\section{Appendix 1}

\section{Nomenclature}

$$
\begin{aligned}
& \mathrm{b} \quad \text { = wing span, } \mathrm{m} \\
& \mathrm{C}_{\mathrm{D}}=\text { drag coefficient } \\
& \mathrm{C}_{\mathrm{L}} \quad=\text { lift coefficient } \\
& \mathrm{C}_{1} \quad \text { = roll moment coefficient } \\
& \mathrm{C}_{\mathrm{M}}=\text { pitch moment coefficient at quarter chord } \\
& \mathrm{C}_{\mathrm{N}} \quad \text { = yaw moment coefficient } \\
& \mathrm{C}_{\mathrm{Y}} \text { = side-force coefficient } \\
& \mathrm{C} \text { = aerodynamic chord, } \mathrm{m} \\
& \operatorname{Re} \quad=\text { Reynolds number, } \rho \mathrm{Vc} / \mu \\
& \mathrm{S}=\text { Planform area, } \mathrm{m}^{2} \\
& \text { aoa = angle of attack, degree } \\
& \mathrm{M}=\text { Mach number } \\
& \mathrm{C}_{\text {Dmin }}=\text { minimum drag coefficient } \\
& \mathrm{C}_{\mathrm{L}, \max }=\text { maximum lift coefficient } \\
& \mathrm{C}_{\mathrm{L}} \alpha, \mathrm{C}_{\mathrm{L}} \beta, \mathrm{C}_{\mathrm{L}} \gamma=\text { wing lift curve slopes } \\
& \mathrm{C}_{\mathrm{D}} \alpha, \mathrm{C}_{\mathrm{D}} \beta, \mathrm{C}_{\mathrm{D}} \gamma=\text { wing drag curve slopes } \\
& \mathrm{C}_{\mathrm{M}} \alpha, \mathrm{C}_{\mathrm{M}} \beta, \mathrm{C}_{\mathrm{M}} \gamma=\text { wing pitching moment curve slopes } \\
& \mathrm{C}_{\mathrm{Y}} \alpha, \mathrm{C}_{\mathrm{Y}} \beta, \mathrm{C}_{\mathrm{Y}} \gamma=\text { wing side force curve slopes } \\
& \mathrm{C}_{1} \alpha, \mathrm{C}_{1} \beta, \mathrm{C}_{1} \gamma=\text { wing roll moment curve slopes } \\
& \mathrm{C}_{\mathrm{N}} \alpha, \mathrm{C}_{\mathrm{N}} \beta, \mathrm{C}_{\mathrm{N}} \gamma=\text { wing yaw moment curve slopes } \\
& \alpha=\text { pitch angle, deg. } \\
& \beta=\text { roll angle, deg. } \\
& \gamma \text { = yaw angle, deg. }
\end{aligned}
$$




\section{Appendix 2}

Table 4. Flat plate wing aerodynamic stability derivatives in the linear portions of the graphs for all aerodynamic components (Unit is per degree)

\begin{tabular}{|c|c|c|c|c|c|c|}
\hline Angles & $C_{L \alpha}$ & $C_{D \alpha}$ & $C_{M \alpha}$ & $C_{Y \alpha}$ & $C_{l \alpha}$ & $C_{N \alpha}$ \\
\hline $\begin{array}{l}\beta=\gamma \\
=0^{\circ}\end{array}$ & $\begin{array}{l}0.0528697 \\
(0 \geq \alpha \\
\geq-10) \\
0.0549925 \\
(0 \leq \alpha \leq 10)\end{array}$ & $\begin{array}{l}-0.0210642 \\
(-8 \geq \alpha \\
\geq-15) \\
0.0167611 \\
(8 \leq \alpha \leq 15)\end{array}$ & $\begin{array}{l}-0.017033 \\
(-8 \geq \alpha \\
\geq-15) \\
0.0027024 \\
(-5 \leq \alpha \leq 5) \\
-0.0110713 \\
(8 \leq \alpha \leq 15)\end{array}$ & & & \\
\hline Angles & $C_{L \gamma}$ & $C_{D \gamma}$ & $C_{M \gamma}$ & $C_{Y \gamma}$ & $C_{l \gamma}$ & $C_{N \gamma}$ \\
\hline $\begin{array}{l}\alpha= \\
\beta=0^{\circ}\end{array}$ & & & & $\begin{array}{l}-0.0000143 \\
(10 \leq \alpha \leq 20)\end{array}$ & & $\begin{array}{l}0.0000733 \\
(-5 \leq \alpha \\
\leq 20)\end{array}$ \\
\hline $\begin{array}{l}\beta=0^{\circ} \alpha \\
=5^{\circ}\end{array}$ & $\begin{array}{l}0.000159293 \\
(0 \leq \alpha \leq 15) \\
-8.598 \mathrm{E}-05 \\
(15 \leq \alpha \leq \\
20)\end{array}$ & $\begin{array}{c}0.000058886 \\
(10 \leq \alpha \\
\leq 20)\end{array}$ & $\begin{array}{l}0.000477826 \\
(10 \leq \alpha \leq \\
20) \\
-9.045 \mathrm{E}-05 \\
(0 \geq \alpha \geq-5)\end{array}$ & $\begin{array}{l}-0.000104858 \\
(10 \leq \alpha \\
\leq 20)\end{array}$ & $\begin{array}{l}0.001648672 \\
(-5 \leq \alpha \leq \\
10)\end{array}$ & $\begin{array}{l}0.000204667 \\
\quad(-5 \leq \alpha \\
\leq 20)\end{array}$ \\
\hline $\begin{array}{l}\beta=0^{\circ} \alpha \\
=10^{\circ}\end{array}$ & $\begin{array}{l}-0.00074144 \\
(0 \leq \alpha \leq 5) \\
0.00264214 \\
(10 \leq \alpha \leq \\
15) \\
-0.00074144 \\
(15 \leq \alpha \leq \\
20)\end{array}$ & $\begin{array}{l}-0.002385782 \\
(15 \leq \alpha \leq \\
20)\end{array}$ & $\begin{array}{l}0.004123282 \\
(0 \leq \alpha \leq 10) \\
-0.00046808 \\
(0 \geq \alpha \geq-5)\end{array}$ & $\begin{array}{c}0.00010029617 \\
-5 \leq \alpha \leq 5) \\
0.005766376 \\
15 \leq \alpha \leq 20)\end{array}$ & $\begin{array}{l}0.006792955 \\
\quad(-5 \leq \alpha \\
\leq 10)\end{array}$ & $\begin{array}{l}0.001096801 \\
\quad(-5 \leq \alpha \\
\quad \leq 5)\end{array}$ \\
\hline $\begin{array}{l}\beta=0^{\circ} \alpha \\
=15^{\circ}\end{array}$ & $\begin{array}{l}0.03101682 \\
(0 \leq \alpha \leq 5) \\
-0.03912328 \\
(5 \leq \alpha \leq 10)\end{array}$ & $\begin{array}{l}0.0076776 \\
(0 \leq \alpha \leq 5) \\
-0.00988834 \\
(5 \leq \alpha \leq 10)\end{array}$ & $\begin{array}{l}0.013779212 \\
(5 \leq \alpha \leq 10) \\
-0.007133746 \\
(0 \leq \alpha \leq 5)\end{array}$ & $\begin{array}{l}0.000528704 \\
(-5 \leq \alpha \leq 5) \\
0.007478717 \\
(15 \leq \alpha \\
\leq 20)\end{array}$ & $\begin{array}{l}0.012400013 \\
(-5 \leq \alpha \\
\leq 15)\end{array}$ & $\begin{array}{l}- \\
0.002756571 \\
(5 \leq \alpha \\
\leq 15)\end{array}$ \\
\hline Angles & $C_{L \beta}$ & $C_{D \beta}$ & $C_{M \beta}$ & $C_{Y \beta}$ & $C_{l \beta}$ & $C_{N \beta}$ \\
\hline \multicolumn{7}{|l|}{$\begin{array}{c}\alpha= \\
\gamma=0^{\circ}\end{array}$} \\
\hline $\begin{aligned} \gamma & =0^{\circ} \alpha \\
& =5^{\circ}\end{aligned}$ & $\begin{array}{l}0.00038628 \\
(-5 \leq \alpha \leq 0) \\
-0.00264546 \\
(10 \leq \alpha \leq \\
20)\end{array}$ & $\begin{array}{l}-0.000159648 \\
(10 \leq \alpha \\
\leq 20) \\
0.00038628 \\
(-5 \leq \alpha \leq 0)\end{array}$ & $\begin{array}{l}0.000026644 \\
(-5 \leq \alpha \leq 0) \\
-0.00011106 \\
(10 \leq \alpha \\
\leq 20)\end{array}$ & $\begin{array}{l}-0.004326894 \\
\quad(-5 \leq \alpha \\
\leq 10)\end{array}$ & $\begin{array}{l}-0.000137856 \\
\quad(-5 \leq \alpha \\
\quad \leq 20\end{array}$ & $\begin{array}{l}0.000236313 \\
\quad(-5 \leq \alpha \\
\leq 20)\end{array}$ \\
\hline
\end{tabular}




\begin{tabular}{|c|c|c|c|c|c|c|}
\hline $\begin{array}{l}\gamma=0^{\circ} \alpha \\
=10^{\circ}\end{array}$ & $\begin{array}{l}-0.00124168 \\
(0 \leq \alpha \leq 5) \\
0.00216518 \\
(10 \leq \alpha \\
\leq 15) \\
-0.00835308 \\
(15 \leq \alpha \leq \\
20)\end{array}$ & $\begin{array}{l}-0.00010828 \\
(0 \leq \alpha \leq 5) \\
0.000324068 \\
(10 \leq \alpha \\
\leq 15) \\
-0.00059295 \\
(15 \leq \alpha \leq \\
20)\end{array}$ & $\begin{array}{l}-0.000818692 \\
(5 \leq \alpha \leq 10) \\
0.001511566 \\
(10 \leq \alpha \\
\leq 15) \\
-0.000696896 \\
(15 \leq \alpha \leq \\
20)\end{array}$ & $\begin{array}{l}-0.009039305 \\
\quad(-5 \leq \alpha \\
\leq 20)\end{array}$ & $\begin{array}{l}-0.001399671 \\
(-5 \leq \alpha \\
\leq 10) \\
0.000922772 \\
(10 \leq \alpha \\
\leq 15)\end{array}$ & $\begin{array}{l}0.000465975 \\
(15 \leq \alpha \\
\leq 20)\end{array}$ \\
\hline $\begin{array}{l}\gamma=0^{\circ} \alpha \\
=15^{\circ}\end{array}$ & $\begin{array}{l}0.00547322 \\
(10 \leq \alpha \leq \\
15) \\
-0.02243826 \\
(15 \leq \alpha \leq \\
20) \\
-0.01341598 \\
(-5 \leq \alpha \leq 0)\end{array}$ & $\begin{array}{l}0.00108228 \\
(10 \leq \alpha \\
\leq 15) \\
-0.0033077 \\
(-5 \leq \alpha \leq 0) \\
-0.00480876 \\
(15 \leq \alpha \\
\leq 20) \\
\end{array}$ & $\begin{array}{l}-0.00112841 \\
(0 \leq \alpha \leq 5) \\
0.006608058 \\
(10 \leq \alpha \\
\leq 15) \\
0.002216986 \\
(15 \leq \alpha \\
\leq 20)\end{array}$ & $\begin{array}{l}-0.012719271 \\
(-5 \leq \alpha \leq 20\end{array}$ & $\begin{array}{l}- \\
0.005375905 \\
(-5 \leq \alpha \\
\leq 10) \\
0.00204798 \\
(10 \leq \alpha \\
\leq 15)\end{array}$ & $\begin{array}{l}0.003478072 \\
(-5 \leq \alpha \\
\leq 0) \\
- \\
0.003800435 \\
(0 \leq \alpha \leq 5)\end{array}$ \\
\hline Angles & $C_{L \gamma}$ & $C_{D \gamma}$ & $C_{M \gamma}$ & $C_{Y \gamma}$ & $C_{l \gamma}$ & $C_{N \gamma}$ \\
\hline $\begin{array}{l}\alpha= \\
5^{\circ} \beta=5^{\circ}\end{array}$ & $\begin{array}{l}0.00512057 \\
(-10 \leq \alpha \leq \\
10)\end{array}$ & $\begin{array}{l}0.000924473 \\
(-10 \leq \alpha \leq \\
10)\end{array}$ & $\begin{array}{l}0.000246653 \\
(-10 \leq \alpha \leq \\
20)\end{array}$ & $\begin{array}{l}-0.000225002 \\
(-10 \leq \alpha \leq \\
-5) \\
4.307 \mathrm{E}-05 \\
(5 \leq \alpha \leq 10)\end{array}$ & $\begin{array}{l}0.001707302 \\
(-5 \leq \alpha \leq \\
10)\end{array}$ & $\begin{array}{l}- \\
0.000234345 \\
(-5 \leq \alpha \leq \\
10)\end{array}$ \\
\hline $\begin{array}{l}\alpha=- \\
5^{\circ} \beta=- \\
5^{\circ}\end{array}$ & $\begin{array}{l}-0.00498581 \\
(-10 \leq \alpha \leq \\
10)\end{array}$ & $\begin{array}{l}0.000886952 \\
(-10 \leq \alpha \leq \\
10)\end{array}$ & $\begin{array}{l}-0.0004609 \\
(5 \leq \alpha \leq 10)\end{array}$ & $\begin{array}{l}-0.0002692 \\
(-10 \leq \alpha \leq \\
-5) \\
0.009257408 \\
(5 \leq \alpha \leq 10)\end{array}$ & $\begin{array}{l}-0.001874381 \\
(-5 \leq \alpha \leq \\
10)\end{array}$ & $\begin{array}{l}-0.00023524 \\
(-5 \leq \alpha \leq \\
10)\end{array}$ \\
\hline
\end{tabular}

